\title{
Large-scale citizen science provides high-resolution nitrogen dioxide values and health impact while enhancing community knowledge and collective action
} \author{
Mark J. Nieuwenhuijsen ${ }^{\mathrm{e}}$, Marta Cirach $^{\mathrm{e}}$, Carolyn Daher $^{\mathrm{e}}$, Jaume Targa ${ }^{\mathrm{f}}$, Anna Ripoll ${ }^{\mathrm{f}}$ \\ a Departament de Física de la Matèria Condensada, Universitat de Barcelona, Martí i Franquès, 1, 08028 Barcelona, Catalonia, Spain \\ ${ }^{\mathrm{b}}$ Universitat de Barcelona Institute of Complex Systems, Catalonia, Spain \\ c Internet Interdisciplinary Institute, Universitat Oberta de Catalunya, Rambla del Poblenou, 156, 08018 Barcelona, Catalonia, Spain \\ d Environmental and Radiological Health Sciences, Colorado State University, 1601 Campus Delivery, 80523 Fort Collins, USA \\ e Barcelona Institute for Global Health (ISGLOBAL), Doctor Aiguader, 88, 08003 Barcelona, Catalonia, Spain \\ f 4sfera Innova, 17002 Girona, Catalonia, Spain
}

Josep Perelló a,b,* , Anna Cigarini ${ }^{\text {a,b,c }}$, Julián Vicens ${ }^{\text {a,b }}$, Isabelle Bonhoure ${ }^{\mathrm{a}, \mathrm{b}}$, David Rojas-Rueda ${ }^{\mathrm{d}}$,

H I G H L I G H T S

- Citizen science contributes to the effort to lower air pollution in urban areas.

- Citizen science can be valuable in the interplay between advances in exposure assessment and policy.

- Citizen science provides unprecedented high-resolution air pollution levels.

- Citizen science provides updated health impact assessments.

- The success relies on the enhancement of community and individual knowledge.

\section{A R T I C L E I N F O}

\section{Article history:}

Received 19 January 2021

Received in revised form 30 March 2021

Accepted 10 May 2021

Available online 14 May 2021

Editor: Lidia Morawska

\section{Keywords:}

Citizen science

Air quality

Health impact assessment

Schools

Asthma

City

\section{G R A P H I C A L A B S T R A C T}
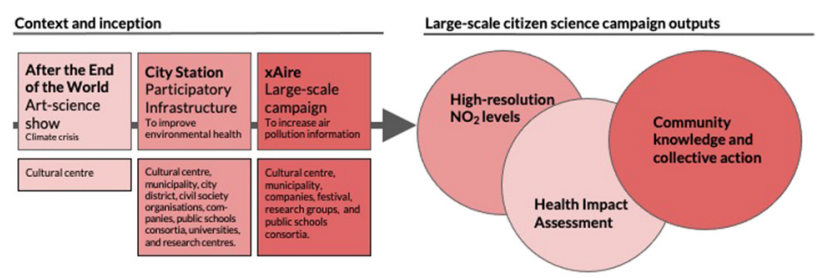

Participatory research process
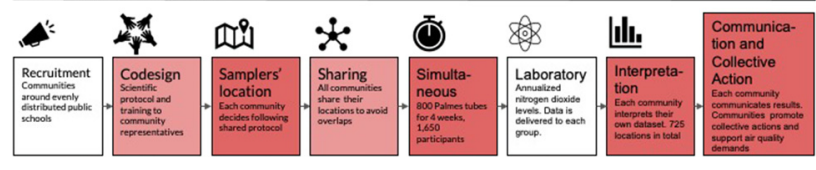

\begin{abstract}
A B S T R A C T
We present outcomes from a large-scale air quality citizen science campaign (xAire, 725 measurements) to demonstrate its positive contribution in the interplay between advances in exposure assessment and developments in policy or collective action. A broad partnership with 1,650 people from communities around 18 primary schools across Barcelona provided the capacity to obtain unprecedented high-resolution $\mathrm{NO}_{2}$ levels and an updated asthma Health Impact Assessment. It is shown that $\mathrm{NO}_{2}$ levels vary considerably with at some cases very high levels. More than a 1,000 new cases of childhood asthma could be prevented each year by lowering $\mathrm{NO}_{2}$ levels. Representativity of site selection and the minimal number of samplers for land use regression modelling are considered. Enhancement of community knowledge and attitudes towards collective response were observed and identified as key drivers for successful large-scale monitoring campaigns. The results encourage strengthening collaboration with local communities when exploring environmental health issues.
\end{abstract}

(C) 2021 The Authors. Published by Elsevier B.V. This is an open access article under the CC BY-NC-ND license (http://creativecommons.org/licenses/by-nc-nd/4.0/).

\footnotetext{
* Corresponding author at: Departament de Física de la Matèria Condensada, Universitat de Barcelona, Martí i Franquès, 1, 08028 Barcelona, Catalonia, Spain. E-mail address: josep.perello@ub.edu (J. Perelló).
} 


\section{Introduction}

Outdoor air pollution causes 4.6 millions premature deaths worldwide (WHO, 2018) each year and 400,000 premature deaths in Europe, and contributes to cardio-vascular diseases, asthma, allergies, strokes or impediments on cognitive development (EEA, 2019a; Landrigan et al., 2018; Nieuwenhuijsen, 2016; Sunyer et al., 2015; Zhang et al., 2018). Guideline values established by the World Health Organisation (WHO) are very often exceeded by one or multiple air pollutants in urban areas worldwide (WHO, 2018). Nine out of 10 people live in areas above the WHO guidelines.

Among the existing air pollution indicators, nitrogen dioxide $\left(\mathrm{NO}_{2}\right)$ concentration level is considered a key value to evaluate air quality in urban areas, due to its relationship with motor vehicles with internal combustion engine emissions (Carslaw, 2005). According to the European Environment Agency (EEA, 2019a), around 7\% to 8\% of the Europeans living in urban areas, about 25 million people, were exposed to high or very high levels of $\mathrm{NO}_{2}$ concentrations between 2015 and 2017 (above $40 \mu \mathrm{g} / \mathrm{m}^{3}$ ). Exposure to high concentrations of $\mathrm{NO}_{2}$ results in a broad range of environmental health impacts (WHO, 2018), especially affecting vulnerable groups such as elder and younger inhabitants, and is associated with for instance lung cancer risk or childhood asthma (Rojas-Rueda et al., 2012; Khreis et al., 2017; Pierangeli et al., 2020).

Motorized traffic is a main contributor (around 70-80\%) to $\mathrm{NO}_{2}$ levels in cities such as Barcelona (Spain). Barcelona is a compact city that has a very high vehicle density (approx. 9,525 vehicles per $\mathrm{km}^{2}$ ), and the majority of passenger cars are diesel (65\%) (Ajuntament de Barcelona, 2018a; Idescat, 2019). It is also estimated that at least $48 \%$ of Barcelona inhabitants are exposed to high $\mathrm{NO}_{2}$ concentration levels (ASPB, 2018).

In 2017, the annual concentrations of $\mathrm{NO}_{2}$ in Barcelona captured by the two existing traffic automatic monitoring stations were 59 and $52 \mu \mathrm{g} / \mathrm{m}^{3}$ (ASPB, 2018), both above the $40 \mu \mathrm{g} / \mathrm{m}^{3}$ WHO and European Commission (EC) limit values (WHO, 2006; EEA, 2019a). This noncompliance with air quality recommendations has been systematically reported for several years (Síndic de Greuges de, 2019).

It is also well documented that $\mathrm{NO}_{2}$ concentration levels can show strong variations, from one street to another, and thus individual citizen's exposure to air pollution can also vary depending on the location he/she lives, studies or works (Vardoulakis et al., 2003; Cyrys et al., 2012; Wu et al., 2015; Lin et al., 2016). However, the distribution of official air quality stations that comply with EU Legislation (Directive 2008/50/EC of the European Parliament, 2008) is not dense enough to obtain complete or high-resolution data for any city (Vardoulakis et al., 2005; Hafkenscheid et al., 2009; Borge et al., 2014; Duyzer et al., 2015; Santiago et al., 2013; Piersanti et al., 2015; Benavides et al., 2019). For instance, in Barcelona in 2019, there were only seven $\mathrm{NO}_{2}$ air quality monitoring automatic stations (as mentioned, two urban traffic stations in densely populated areas and five urban background stations (ASPB, 2018) for a $101 \mathrm{~km}^{2}$ area, with 1,636,762 inhabitants (Idescat, 2019)).

The low number of $\mathrm{NO}_{2}$ air quality automatic monitors can limit in several ways a robust understanding of air pollution exposure distribution in cities such as Barcelona, and especially when this data is expected to be used to translate air quality levels into health impacts and policy (Benavides et al., 2019).

In terms of public awareness, a recent opinion poll in European cities showed air pollution as the issue of most concern for citizens after climate change (Eurobarometer, 2019). However, a majority of respondents did not feel well-informed about air quality problems in their country, and only around one third of respondents had heard of the European air quality standards. Even with this lack of information, respondents were more likely to think that air quality has deteriorated (58\%) over the past ten years, even though the opposite occurred, and that the European Commission (EC) should propose additional measures to address air quality-related problems in Europe (71\%). Finally,
$38 \%$ of the respondents would like to be able to express their own views on this issue.

Citizen science practices provide a way to actively and collectively respond to air quality issues (EEA, 2019b). Citizen science, broadly defined as the participation of the public in research (Heigl et al., 2019; Auerbach et al., 2019), offers methods to gather massive data and accelerate data processing while elevating public awareness, knowledge, and understanding about scientific methods and the societal relevance of science outcomes (Parrish et al., 2019). There are already a wide range of disciplines and topics that are obtaining significant outcomes thanks to active public involvement in scientific research (Jones and Spiers, 2018; Irwin, 2018).

However, the more popular citizen science is, the more diverse and ambitious it has become, thanks to its interplay between research, society and policy making (Haklay, 2015; Kosmala et al., 2016; Guerrini et al., 2018; MacDonald et al., 2018; Lukyanenko et al., 2019; Shanley et al., 2019; Hecker et al., 2019; Fritz et al., 2019; Koepnick et al., 2019; Mehr et al., 2019). Recent articles illustrate how crowdsourced citizen science data can elucidate opportunity costs and large spatiotemporal representations including: conservation efforts of fisheries (Fairclough et al., 2014), migratory birds species (Schuster et al., 2019), biodiversity in general (Miller et al., 2019; Jetz et al., 2019), mosquito and other organisms control from a public health perspective (Johnson et al., 2018; Palmer et al., 2017; Garcia-Martí et al., 2018), human mobility patterns (Gutiérrez-Roig et al., 2016) or earthquake locations (Steed et al., 2019). These examples, among others, consider and evaluate collective spatial coverage and mapping in one way or another.

For air pollution, citizen science is generally using low-cost sensors. Indeed, connectedness low-cost sensor technologies (Dutta et al., 2009; Kumar et al., 2015; Clements et al., 2017; Castell et al., 2017; Jerrett et al., 2017; Mijling et al., 2018; Wong et al., 2018; Ripoll et al., 2019; Languille et al., 2020) are helping to improve air quality monitoring, transparency, awareness and action between citizens and authorities (Caplin et al., 2019; Wesseling et al., 2019; De Craemer et al., 2020). Cities (Kumar et al., 2015; Longo et al., 2020) and public agencies (EEA, 2019b) are also sharing their environmental exposure data and in some cases to introduce participatory frameworks (Chen et al., 2017). Worldwide, nonprofit organisations (Haklay and Eleta, 2019), public health or environmental agencies (EEA, 2019b), and even self-organised groups are indeed developing citizen science strategies for the interplay between advances in environmental exposure assessment and developments in policy (Kumar et al., 2015; English et al., 2017; Hsu et al., 2017; Wong et al., 2018; Longo et al., 2020; De Craemer et al., 2020). Opportunistic mobile monitoring campaigns are one possible strategy to gather high-quality resolution data (Castell et al., 2015). These campaigns make use of existing mobile infrastructures and people's common daily routines to deploy measurement devices, for example, with the participation of city employees to measure black carbon (Van den Bossche et al., 2016) or determining burden of disease by adding passive sensing of human mobility using cellular phone signals (Yang et al., 2017). Other initiatives enhance their impact on participant's knowledge and attitudes (Schaefer et al., 2020; Golumbic et al., 2019) and untap the potential of incorporating citizens and local communities in research processes (Wong et al., 2018; Mahajan et al., 2020).

The CurieuzeNeuzen citizen science project in Antwerp (517,000 inhabitants), promoted by a group of experts, the Ringland Academy, is a particularly relevant example (Van Brussel and Huyse, 2019). Aiming to provide evidence for capping the traffic rings of the city, the role of civic movement was combined with the role of the knowledge network in order to feed public debate with evidence (Irwin, 2018; De Craemer et al., 2020). CurieuzeNeuzen later evolved to the wider Flanders region of Belgium (Irwin, 2018; EEA, 2019b; De Craemer et al., 2020). Another example is Mapping For Change (Haklay and Eleta, 2019). The organisation has intervened in different locations worldwide, including periodic greater London campaigns or specific campaigns in African cities where citizen science collected ambient concentrations might be the only air 
quality records available (Haklay and Eleta, 2019). Mapping for Change takes collective mapping and community-based research approaches, and their campaigns show wider implications in aspects such as scientific literacy (Kloetzer et al., 2017).

These two initiatives both use Palmes diffusion tubes for monitoring $\mathrm{NO}_{2}$ concentration levels (Palmes et al., 1976; EEA, 2019b). For massive campaigns, Palmes diffusion tubes are found to be more adequate than other low-cost as they are very cheap, 10 or 100 times cheaper than other low-cost sensors (EEA, 2019b). Palmes tubes are also included in the European Air Quality directives as a complimentary technique and they are comparable to $\mathrm{NO}_{2}$ annual average, which is a key and easy-to-understand value both for citizens and public bodies (EEA, 2019b). Albeit not showing real-time data, Palmes tubes are also more attractive than other low-cost sensors as they are ready-to-use with no need of power grid or internet access. The latter characteristics increase flexibility when working together with communities such as families with very young kids (aged between 7 and 12 years old). The choice is reinforced by the fact that the deployment of Palmes tubes does not require of any intensive training nor any intensive and longterm engagement.

The main goal of the current paper is thus to jointly present the results of the xAire citizen science project. We pay special attention to three key interdependent aspects that, from our perspective, can make citizen science practices an attractive approach to face air quality issues in our cities: (1) an unprecedented, reliable, and representative highresolution air pollution level data; (2) an updated high-resolution air pollution exposure for Health Impact Assessment (HIA) in the case of asthma; and (3) an enhancement of community (and individual) knowledge and attitudes towards city-level collective responses to air quality issues. The main reason for this multifaceted approach in a single paper is precisely because it is at this broad level where potential of air quality citizen science initiatives can be fully perceived.

\section{Material and methods}

The $x$ Aire project was conceived as a pop-up citizen science initiative (Sagarra et al., 2016) within the City Station (a participative community-based initiative) as part of the After The End of The World exhibition at the Centre de Cultura Contemporània de Barcelona (an important exhibition venue in Barcelona, 2017-2018). A pop-up citizen science initiative is defined by Sagarra et al. (2016) as non-permanent, highly participatory collective experiments and it does not require of a long-term participants' engagement to succeed in the research goals being planned. Under the general framework of art-science hybrized initiatives (e.g., Perelló et al. (2012)), several participatory research activities were taking place at the City Station, and the xAire project was the most ambitious one.

A broad partnership was established to launch the xAire project with more than 1,650 participants, 10 professional research scientists (the authors of this article), about 36 teachers and 4 non-scientific organisations. To articulate this large participation and catalyze its impact in the city, the xAire project opted to make a general call to families through primary schools (with children between 7 and 12 years old) with a similar spirit to other experiences with students that link popular epidemiology and community-based research (Steiner, 2020). The xAire project was built as an opportunity for families to meet and work together in an inclusive after-class activity that enabled families to directly intervene in a topic related to the health of their children (e.g., asthma).

As a partner of the xAire project, the Barcelona Education Consortia (public schools' municipal network, Consorci d'Educació de Barcelona, CEB) engaged 18 primary public schools evenly distributed among the 10 districts of the city. Provided with a methodology guideline (Perelló et al., 2018, and MethodsX), after a training session and in a coordinated manner, the schools organised mixed groups of 4-5 people with parents and children and autonomously placed up to 800 Palmes passive diffusion tube $\mathrm{NO}_{2}$ samplers following identical protocol and resulting in 725 valid data points (671 outdoor, 31 outdoor playground, and 23 indoor school, between February 16th and March 15th, 2018, four weeks). In the case of Barcelona, large simultaneous sampling has only been conducted by professional scientists, and it has never reached more than 300 sampling points (Benavides et al., 2019). Each of the schools interpreted the data and provided a set of conclusions and demands during the Barcelona Science Congress, where young students were the presenters and the attendants, with the presence of the Barcelona Mayor. The schools also promoted the organisation of a non-initially planned event at the Town Hall where representatives for each school delivered results and demands to the Deputy Mayor of Ecology, Urbanism and Mobility, and the Commissioner of Ecology. Data was finally uploaded onto a digital mapping platform for public consultation (xAire, 2018). Broad press coverage reported this unprecedented effort in the city of Barcelona throughout the project (e.g., InfoK (2018) and ARA (2018)).

Cost-effectiveness and the simplicity of the Palmes passive samplers (Palmes et al., 1976) facilitates the inclusion of large numbers of citizens in a study that can bring several benefits to society while providing new scientific insights (Caplin et al., 2019; De Craemer et al., 2020). However, compared to citizen science initiatives in other fields or topics, studies to demonstrate on a large scale (city level) the full potential of citizen science for air quality monitoring are still scarce and partial (De Craemer et al., 2020). Some studies have focused on the methods and strategies being deployed (Haklay and Eleta, 2019; Van Brussel and Huyse, 2019), while others on data quality and standards compliance (De Craemer et al., 2020). Others show their societal impact through interviews (Schaefer et al., 2020) or highlight the need to take an inclusive approach in research design (Golumbic et al., 2019; Mahajan et al., 2020).

\subsection{Participatory process}

Fig. 1 summarizes the different phases of the xAire research process, including co-definition and interaction with participants to select sampling sites, from the project inception to results interpretation that were publicly shared and motivated collective actions. Appendices provide detailed information on where the xAire project was created, on the preliminary test serving as a participatory prototyping effort, and on public presentations of the results.

Through the Barcelona Education Consortia (Consorci d'Educació de Barcelona, $\mathrm{CEB}$ ) we firstly explored the potential interest of schools and families to participate in the xAire project. An initial meeting was organised on November 30th, 2017 with Primary school teachers. The feedback was very positive and enthusiastic. Due to logistics and budgetary limitations, the CEB chose between one and two schools per district based on the strength of their commitment and their diversity (18 in total). Primary schools were engaged through their teachers and decided which specific classes and groups from their schools would participate and then invited families to join. The list of 18 schools with its code name, district, grade and age range is reported in Table 1.

A massive afternoon training session for teachers and families was then organised and the whole scientific protocol was discussed with more than 200 educators and family representatives from all 18 schools engaged (January 18th, 2018). The training session used an assembly format and included key aspects of Palmes diffusion tubes samplers (see Section 2.2 Measurement technique). After the session, the protocol was revised again and sent via email to the focal points established at each school. The protocol guide included the objectives of the initiative, a description of the key players, a calendar with milestones, and a detailed, step-by-step description on how and where to place the diffusion tubes (Perelló et al., 2018, and Methods X).

Each class group was asked to plot the 40 tube samplers on a map during class hours, at home (with families), and eventually during a walk in their respective neighborhoods. They chose their preferred locations through discussions with teachers and families in accordance with 


\begin{tabular}{l}
$\begin{array}{l}\text { After the End } \\
\text { of the World } \\
\text { Art-science } \\
\text { show } \\
\text { Climate crisis }\end{array}$ \\
\hline Cultural centre \\
\hline
\end{tabular}

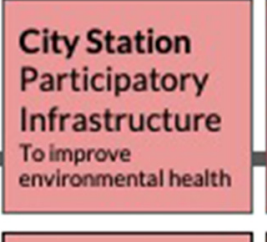

Cultural centre municipality, city district, civil society organisations, com: panies, public schools panies public schools and research centres.
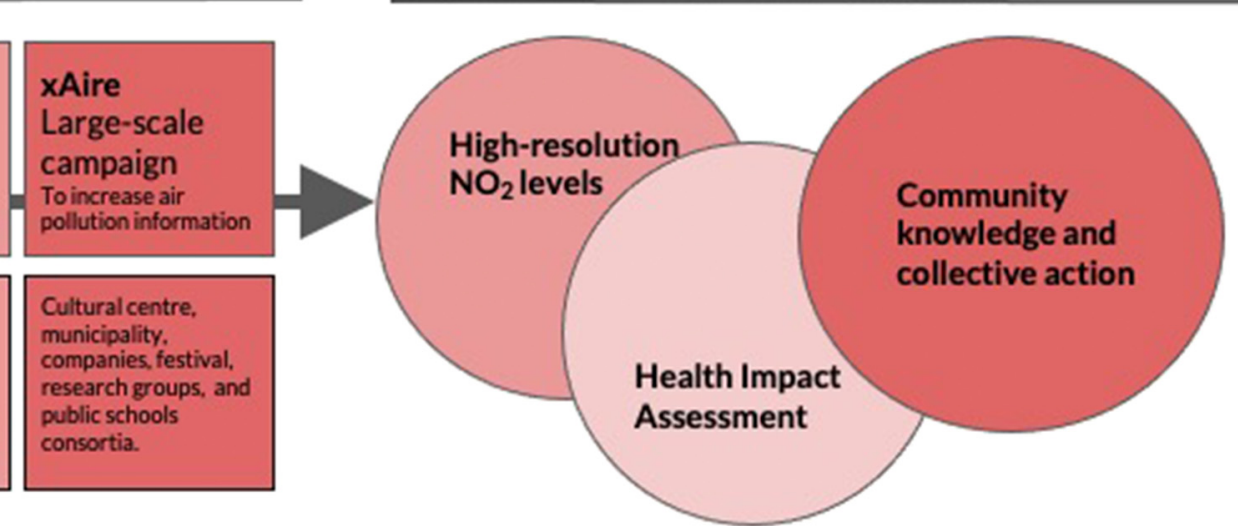

\section{Participatory research process}

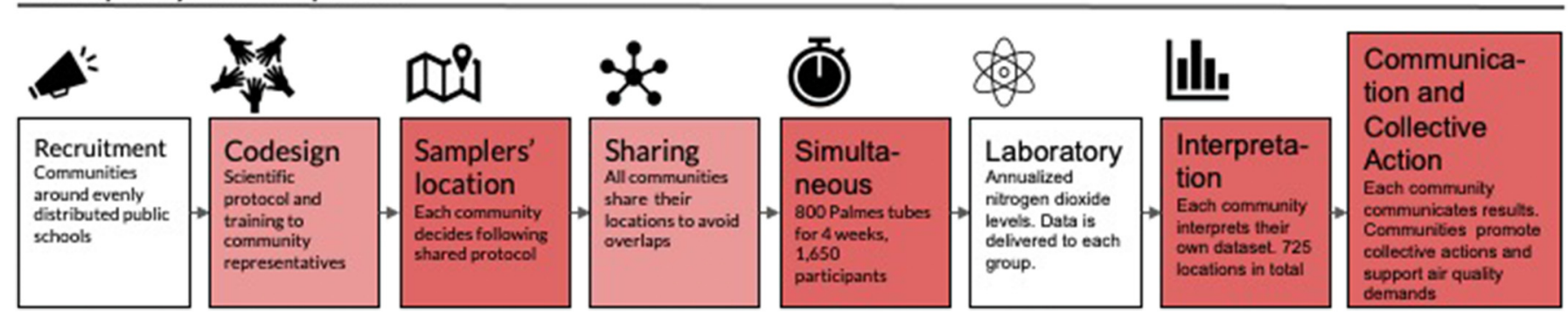

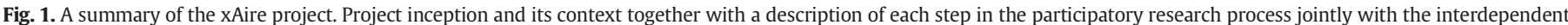
outputs of its large-scale air quality citizen science campaign. Color intensity grades the intensity level of participation of the schools. See also Appendix A, B and C.

the following criteria: 1) each school had to include one location at the main entrance of the school, one at the playground and one indoors; 2 ) the rest of the samplers were to be deployed outdoors aiming to achieve background (at least $10 \%$ of the samplers $300 \mathrm{~m}$ away from motorized roads) and traffic-orientated locations, avoiding specific spots such as bus stations and intersections, and placing tubes at least $100 \mathrm{~m}$ distance apart from each other. One week before starting the collective sampler placement, and to avoid overlaps or anticipate problems, each school delivered a map to the xAire coordination team indicating where their tubes would be located. An overlap in the locations in two schools and a too dense tube's distribution in one school were detected. These resulted in a revision of half a dozen sampler locations.

\section{Table 1}

List of public primary schools involved in the xAire project. The columns include information related to the code name used, the district, the age range (in years old), the grade of the students.

\begin{tabular}{llllll}
\hline & Primary school & Code & District & Age & Grade \\
\hline 1 & Els Horts & EH & Sant Martí & $10-12$ & 5 th, 6th \\
2 & Sant Martí & SM & Sant Martí & $10-11$ & 5 th \\
3 & El Sagrer & ES & Sant Andreu & $11-12$ & 6 th \\
4 & Can Fabra & CF & Sant Andreu. & $11-12$ & 6 th \\
5 & Calderón de la Barca & CA & Nou Barris & $7-8$ & 2nd \\
6 & Timbaler del Bruc & TB & Nou Barris & $9-10$ & 4 th \\
7 & Pau-Casals & PC & Gràcia & $8-9$ & 3rd \\
8 & Sagrada Família & SF & Gràcia & $9-10$ & 4 th \\
9 & Joan Miró & JM & L'Eixample & $7-8$ & 2 nd \\
10 & Fort Pienc & FP & L'Eixample & $11-12$ & 6 th \\
11 & Dolors Monserdà Santa Pau & DM & Sarrià-Sant Gervasi & $11-12$ & 6 th \\
12 & Seat & SE & Sants-Montjuïc & $9-10$ & 4 th \\
13 & Àngels Garriga & AG & Horta-Guinardó & $10-11$ & 5 th \\
14 & Coves d'en Cimany & CC & Horta-Guinardó & $10-11$ & 5 th \\
15 & Àngel Baixeras & AB & Ciutat Vella & $11-12$ & 6 th \\
16 & Cervantes & CE & Ciutat Vella & $11-12$ & 6 th \\
17 & Les Corts & LC & Les Corts & $11-12$ & 6 th \\
18 & Lavínia & LA & Les Corts & $11-12$ & 6 th \\
\hline
\end{tabular}

School representatives came to pick their 40 samplers on February 15th, 2018, one day before deployment. This meeting served to finalize logistics details and resolve remaining doubts or questions. The samplers were installed simultaneously on Friday, February 16th, 2018, around $5 \mathrm{pm}$, and they were removed 4 weeks later (the optimal time window to maximize Palmes diffusion tubes precision (De Craemer et al., 2020)). Groups spent up to $2 \mathrm{~h}$ to complete their deployment routes.

As described in the protocol (Perelló et al., 2018, and Methods X), each group brought a small ladder to place the samplers at approximately $2.20 \mathrm{~m}$ high with their clip. Each tube was identified with a four-digit numeric label. The participants then completed a paperbased table with the following information: the address and the GPS coordinates (using their own mobile phones) together with the reference code of each tube. Each sampler was also classified depending on its location: indoor (inside the school), playground (outdoor), outdoor urban traffic and outdoor urban background. The same operation was repeated during sampler removal (March 15th, 2018).

Installation and removal forms were completed using a double check procedure: using mobile phones, participants took a picture of each tube (clearly identified) in its location. Each school uploaded all documentation into an online form jointly with scanned versions of the paper tables to double check any inconsistencies.

\subsection{Measurement technique}

Ambient concentrations of $\mathrm{NO}_{2}$ were measured using Palmes-type $\mathrm{NO}_{2}$ diffusion tubes (Palmes et al., 1976). These passive air quality samplers absorb the pollutant to be monitored directly from the surrounding air and need no power supply. They consist of an acrylic tube $7.1 \mathrm{~cm}$ long and $1.1 \mathrm{~cm}$ internal diameter, two stainless steel grids and two caps. A chemical reagent is used to absorb the pollutant to be measured directly from the air. The absorbent used is $20 \%$ triethanolamine (TEA) deionized water. The stainless-steel grids at the closed end of the tube are coated with this absorbent. The transport of $\mathrm{NO}_{2}$ through 
the tube is done by molecular diffusion process (Targa and Loader, 2008), since during sampling one end is open and the other closed. After sampling, the exposed tubes are analyzed using a Spectrophotometric technique. The concentrations of Nitrite ions, and hence $\mathrm{NO}_{2}$, chemically adsorbed are quantitatively determined by UV/Visible Spectrophotometry with reference to a calibration curve derived from the analysis of standard nitrite solutions (UKAS Accredited Methods).

Passive sampler technique has both advantages and limitations when compared to reference automatic analysers. Main advantage is that passive samplers are easy to use and relatively inexpensive, so they can be deployed in large numbers over a wide area, giving good spatial coverage. These are often used to complement more expensive automatic monitoring techniques, or at locations where it would not be feasible to install an automatic monitor. In citizen science projects, for example, this technique is ideal to cover wide areas involving large number of participants. Passive samplers being used in this paper also have two limitations. First limitation is that passive samplers are categorised as an "indicative" monitoring technique, which refers to a technique with relatively high uncertainty $( \pm 25 \%$ according to EU CAFÉ Directive (Kuklinska et al., 2015)). While ideal for screening surveys, or for identifying locations where $\mathrm{NO}_{2}$ concentrations are highest, they do not provide the same level of accuracy as automatic reference monitoring techniques ( $\pm 10 \%$ according to EU CAFÉ Directive). The passive samplers' technique can thus be used to complement official networks but not to substitute reference methods. Second limitation is related to the time resolution. As the exposure period is typically several weeks, the results cannot be compared with air quality standards and levels based on shorter averaging periods such as hourly (Targa and Loader, 2008). However, they are fully comparable to long term limit values like annual average, as presented in this paper. Further details on accuracy limitations in relation to annual average are provided in the following section.

\subsection{Data precision and accuracy}

Diffusion tube precision can be described as the ability of a measurement to be consistently reproduced, i.e., how similar the results of triplicate tubes are to each other. This is calculated with the coefficient of variation $(\mathrm{CV})$ of triplicate tubes results. Passive samplers may under or over-estimate $\mathrm{NO}_{2}$ concentrations, resulting in a relatively moderate uncertainty. For this reason, during the measurement campaign, diffusion tubes were exposed in triplicate at 8 reference automatic official monitoring stations in the study area (one was very close but outside the Barcelona municipality). The monitoring stations included different types of stations classification according to European directive (Directive 2008/50/EC of the European Parliament, 2008): urban traffic (3) and urban background (5). The co-location with automatic monitors allowed calculating the precision and accuracy (bias).

A "good" precision applies where the average CV of all triplicate results is less than 10\% (LAQMTG16, 2018). In this study, the average CV was $3.9 \%$, with a range between 0.9 and $7.8 \%$, indicating a good precision. The accuracy of diffusion tubes (bias) represents the overall tendency of the diffusion tubes to depart from the true value, i.e., to under or over-read relative to the reference method (the chemiluminescence analyser). In this case the average bias adjustment factor was 1.07 , which means that tubes underestimated $7 \%$ of $\mathrm{NO}_{2}$ concentrations, so the results were adjusted using this factor. This bias implies an uncertainty within $\pm 10 \%$ which therefore represents a good accuracy level. The accuracy was calculated in relation to the raw 4 weekly measurements from the automatic reference stations and during exactly the same monitoring period.

It is also true that seasonal variation of $\mathrm{NO}_{2}$ levels may influence short term monitoring campaigns. As long-term health effects are either based on hourly or annual $\mathrm{NO}_{2}$ averages, it is then advisable to adjust data to an annual mean. This adjustment removes influences by the environmental conditions of the monitoring period which may not be representative of the annual levels. The results of the 4 weeks measurement campaign carried out in February-March 2018 could be influenced by the environmental conditions of this period and may not be representative of the annual mean. Thus, the results were adjusted to estimate an annual mean concentration using the $2017 \mathrm{NO}_{2}$ annual mean at each reference station. The average ratio between annual means and period means was 0.96 , which in turn was used as an adjustment factor to our passive samplers' data.

As a further control measure, travel blanks were used across the study to detect any contamination during the shipping. The results of the blanks were below the detection limit. Key meta-information was also collected for each site by each school during the deployment and collection: site name, site type, latitude and longitude. The exact location of the sites was obtained by different means: GPS readings on site using phones or tablets or using desktop tools like Google Maps. The team reviewed all site locations on a semi-manual process to ensure all locations were reported accurately, which was the case for more than $90 \%$ of the samplers.

\subsection{Land use regression model}

The Land Use Regression model (LUR) approach was used to create an air quality map and determine the exposure assessment to $\mathrm{NO}_{2}$ using the xAire data. LUR is a statistics-based method often used in epidemiologic studies to predict the air pollution exposures. This is based on true air pollution data measured on a certain number of sites and a set of predictor variables available through Geographic Information Systems (GIS) characterizing the surrounding environment (Cyrys et al., 2012; Eeftens et al., 2012).

671 outdoor samplers were initially considered for the LUR model. We retrieved traffic intensity data at street level (Ajuntament de Barcelona, 2014), land use data (EEA, 2012), population density (Idescat, 2018), buildings density (ICC, 2015), elevation data from a regional digital elevation model (DEM) at $15 \mathrm{~m}$ resolution (ICC, 2021), site type characterization (traffic or background) and district zone where sampler was located. Based on several studies (Ryan and LeMasters, 2007; Hoek et al., 2008; ESCAPE, 2013) predictor variables at different buffered sizes (i.e., 50, 100, 300,500, and 1,000) were constructed at all geographical sampling locations with above mentioned information and offered to the model. A supervised stepwise procedure was followed to select the variables that provide a better model performance. Statistic model diagnostics were tested for influential observations, heteroscedasticity and normality of residuals and spatial autocorrelation. Model sample selection was made following a wellestablished stepwise method with predefined rules, the complete manual where all procedure is explained can be found at ESCAPE (2013).

Standard validation tests such as normality, influential observations, heteroscedasticity and spatial autocorrelation were derived. Model validation was carried out with a leave-one-out cross-validation. Once the model is established, one observation is being removed and the same model is tested with the remaining set of observations ( $n-1)$. This operation is repeated iteratively for all the observations and finally an averaged R2 from all the previous models is computed and reported as the $\mathrm{R} 2$ cross-validation. Spatial autocorrelation of residuals is tested during the model diagnostics using Moran I test as shown in Fig. S5 in the Supplementary Material. We there also provide information on the generalized additive model (GAM) being used and diagnostic information about the LUR fitting procedure and its results with plots of residual performance.

\subsection{Health impact assessment}

We estimated the $\mathrm{NO}_{2}$ exposure on census tract level using the LUR model developed within the present study. Population data for 2018 on census tract level for Barcelona was obtained from the national statistical records (INE, 2011), and we selected the child population with an 
age equal or below 18 years old. Health data on asthma incidence rates (based on doctor's diagnosed asthma) were collected for the specific age group (1-18 years old) for males and females in Spain from the Global Burden of Disease project (GBD, 2016).

As described in Fig. S4, a comparative health risk assessment approach was applied to estimate the number of asthma cases attributable to $\mathrm{NO}_{2}$ (Rojas-Rueda et al., 2012; Pierangeli et al., 2020). Two scenarios were created, scenario 1) achieving the average annual recommended guideline exposure levels for $\mathrm{NO}_{2}\left(40 \mu \mathrm{g} / \mathrm{m}^{3}\right)$ from the WHO guidelines (WHO, 2006); and scenario 2) achieving the minimum reported levels of $\mathrm{NO}_{2}\left(1.5 \mu \mathrm{g} / \mathrm{m}^{3}\right)$ from a meta-analysis (Khreis et al., 2017). The exposure-response function between $\mathrm{NO}_{2}$ and the development of asthma in children between the ages of 1 to 18 is based on 20 studies and equaled $\mathrm{OR}=1.05$ (95\% CI, 1.02-1.07) per each increment in the exposure to $4 \mu \mathrm{g} / \mathrm{m}^{3}$ (Khreis et al., 2017). This translates to a $5 \%$ increase in childhood asthma per $4 \mu \mathrm{g} / \mathrm{m}^{3}$ increase in $\mathrm{NO}_{2}$.

The exposure-response function is used to estimate the relative risk (RR) of developing asthma for $\mathrm{NO}_{2}$ and corresponding scenario by census tract (Khreis et al., 2017). Then each RR is used to estimate the corresponding Population Attributable Fraction (PAF) for each scenario and pollutant. Finally, the PAF was combined with asthma cases, calculated for children between 1 and 18 years old in each census tract in Barcelona to estimate the attributable asthma cases for each level of exposure and census tract, and subsequently summed up to get a total for Barcelona.

Data treatment, model development and mapping were carried out using R Core Team (2019), Python Software Foundation (2021), PostgreSQL (2017), PostGIS (2017) and QGIS (2009).

\section{Results}

Results are structured in three subsections. Firstly, urban $\mathrm{NO}_{2}$ concentration data in a high-resolution level is carefully analyzed and data quality is discussed in terms of reliability and representativeness. Secondly, we show how the large number of spots enriches and updates current Land Use Regression (LUR, e.g., Ryan and LeMasters (2007), Hoek et al. (2008)) models for both air pollution exposure and HIA in the case of asthma disease (for the 1-18 year old population). Thirdly, participants' knowledge and attitudes are reported to provide qualitative evidence on how the xAire project has increased public awareness and promoted bottom-up collective actions to improve air quality.

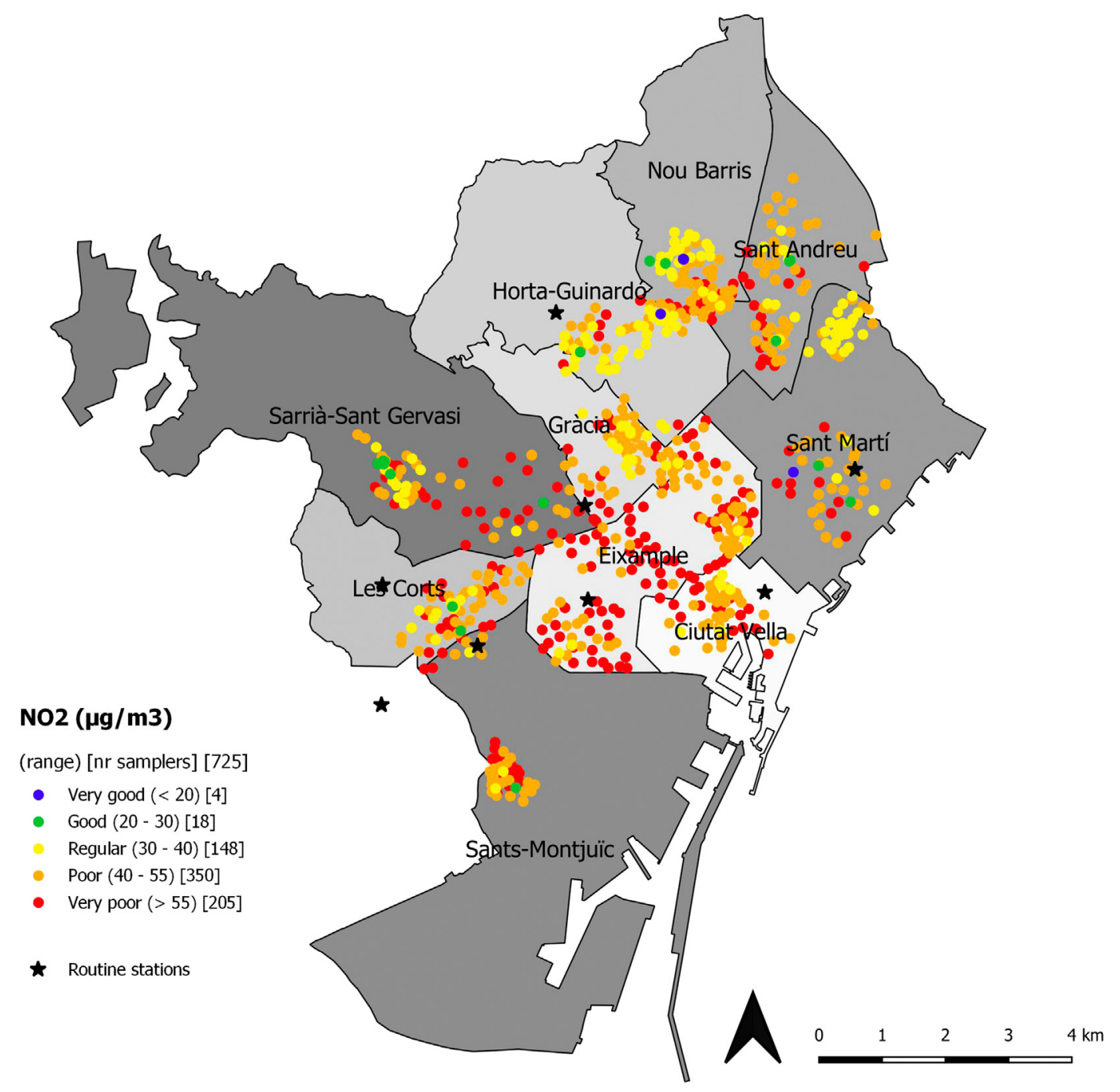

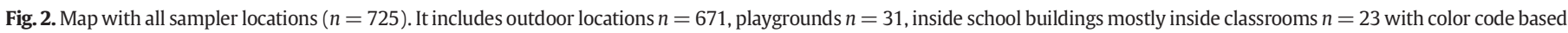

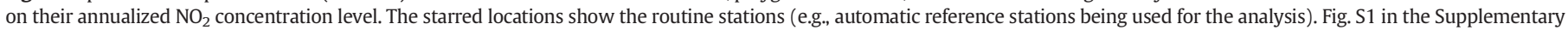

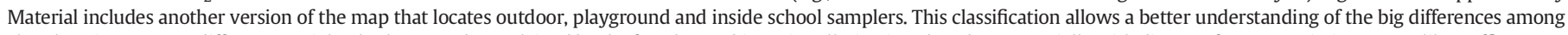

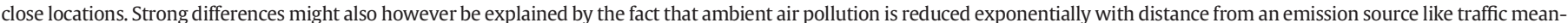

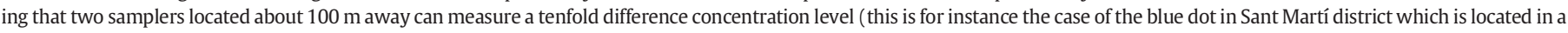

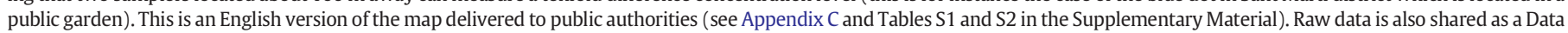
in Brief publication. (For interpretation of the references to color in this figure legend, the reader is referred to the web version of this article.) 


\subsection{High-resolution $\mathrm{NO}_{2}$ concentration levels}

The xAire project distributed a total of 800 passive samplers to different school groups, and this joint effort finally resulted in a total of $725 \mathrm{NO}_{2}$ valid concentration level points (91\% of the total samples, a slightly higher success ratio than a recent even larger air quality citizen science campaign in Belgium (De Craemer et al., 2020)). Fig. 2 shows the map with all samplers' locations selected by participants and Fig. S1 shows outdoor, indoor and playground locations (inside schools).

Fig. 3(a) verifies a high degree of precision and accuracy. It confirms that obtaining very good quality data in large-scale citizen science $\mathrm{NO}_{2}$ campaigns is effectively possible. Furthermore, annual concentration adjustment factor to data can be applied (LAQMTG16, 2018). De Craemer et al. (2020) have recently shown the validity of this extrapolation procedure in a similar large-scale citizen science campaign. We will use the annual adjusted data in all the forthcoming analyses (see Section 2.3 Data precision and accuracy for further details).

Aligned to other studies made with and without citizen science strategies (Vardoulakis et al., 2003; Cyrys et al., 2012; Wu et al., 2015; Lin et al., 2016; De Craemer et al., 2020), Fig. 3(b) shows that passive samplers records describe relevant differences with respect automatic official monitoring stations (averaged annual monitoring reference (ASPB, 2018)). In fact, the average overall passive samplers $\left(49 \pm 1 \mu \mathrm{g} / \mathrm{m}^{3}\right)$ is higher than the Barcelona level averaged over the automatic official monitoring stations $\left(42 \pm 4 \mu \mathrm{g} / \mathrm{m}^{3}, \mathrm{n}=7\right.$, ASPB (2018)). Indeed, $68 \%$ of the xAire outdoor samplers give higher values than the Barcelona level averaged over the seven automatic stations (see Table S1).

Fig. 4 illustrates several statistical aspects related to the xAire passive samplers. Again consistent with current literature (Vardoulakis et al., 2003; Cyrys et al., 2012; Wu et al., 2015; Lin et al., 2016; De Craemer et al., 2020), Fig. 4(a) shows a large range of concentrations ( mean $=49 \pm 1 \mu \mathrm{g} / \mathrm{m}^{3}$, median $=45$, Quartile $1=39$, Quartile $3=$ 55 , Skewness $=1.82$, see Table $\mathrm{S} 1$ ). There is a considerable number of samplers $(5 \%, n=34)$ that have concentration levels higher than $86 \mu \mathrm{g} / \mathrm{m}^{3}$. Fig. 4(b) goes into more detail and discerns between traffic sites (mean $=52 \pm 1 \mu \mathrm{g} / \mathrm{m}^{3}, n=482,5 \%$ of the samplers show higher values than $89 \mu \mathrm{g} / \mathrm{m}^{3}$ ) and background sites (100 m away from streets with motorized vehicles, mean $=41 \pm 1 \mu \mathrm{g} / \mathrm{m}^{3}, n=182,5 \%$ of the samplers show higher values than $56 \mu \mathrm{g} / \mathrm{m}^{3}$ ), thus confirming strong differences persist within this classification (see also Table S1). Averaged annual levels from traffic ( $n=2)$ and background ( $n=5$ ) automatic official monitoring stations (ASPB, 2018) are respectively 56 and $38 \mu \mathrm{g} / \mathrm{m}^{3}$.

Looking at the granularity for the 10 districts, boxplot in Fig. 4(c) and Tables S2 and S3 show that even within each district there exists a strong variability biased towards higher concentration levels. Background concentration levels are generally lower than traffic concentration levels. Fig. 4(c) shows disparity among the 10 districts and this also becomes evident in Table S2 where in 3 districts $5 \%$ of the samplers show values at least higher than $89 \mu \mathrm{g} / \mathrm{m}^{3}$. In one of these 3 districts, $5 \%$ of the samplers have values below $28 \mu \mathrm{g} / \mathrm{m}^{3}$ (the lowest value over all 10 districts).

Schools were also interested in knowing the air quality in their playgrounds $(n=31)$ and inside their schools ( $n=23$, indoor, mostly inside classrooms). The xAire project left the freedom to each school to use some of the samplers for this purpose. $\mathrm{NO}_{2}$ concentration levels are in both cases quite high. The playground outdoor mean level is very close to the EU/WHO threshold ( $37 \pm 1 \mu \mathrm{g} / \mathrm{m}^{3}$, median $=38$, Quartile $1=34$, Quartile $3=40$, see Table $S 1$ ). School indoor samplers broadly show, as expected, lower levels but they are broadly distributed ( $31 \pm$ $3 \mu \mathrm{g} / \mathrm{m}^{3}$, median $=28$, Quartile $1=24$, Quartile $3=36$, Skewness $=$ 2.43 , see Table $\mathrm{S} 1$ ). Both values are positively correlated (Pearson correlation rho $=0.34, n=15$ ). Linear regression $\mathrm{y}=\mathrm{ax}+\mathrm{b}$ of indoor school levels with respect playground levels can also be performed albeit errors are high $\left(\mathrm{a}=0.24 \pm 0.17\right.$ and $\left.\mathrm{b}=28 \pm 5 \mu \mathrm{g} / \mathrm{m}^{3}\right)$.

Regarding the question of whether samplers' location can be considered to be representative, participant's selection may result in underexplored areas and general conclusions from the data collected may be thus questioned. Spatial representativeness is indeed a key question raised in environmental monitoring or collective mapping citizen science projects (Kosmala et al., 2016; Lukyanenko et al., 2019; Fairclough et al., 2014; Schuster et al., 2019; Miller et al., 2019; Jetz et al., 2019; Garcia-Martí et al., 2018; Steed et al., 2019; Dumas et al., 2020; Tiago et al., 2017; Kallimanis et al., 2017). In the context of citizen science and air quality monitoring, there is still limited amount of literature to evaluate this issue. Wong et al. (2018) can be particularly highlighted as it provides a monitor sitting process that successfully integrates community deliberation and scientific priorities for 20 low-cost sensors to evaluate outdoor exposure to particulate matter (PM). In contrast, xAire is being considering a much larger number of samplers' location (725) with a modular community deliberation (inside every a)

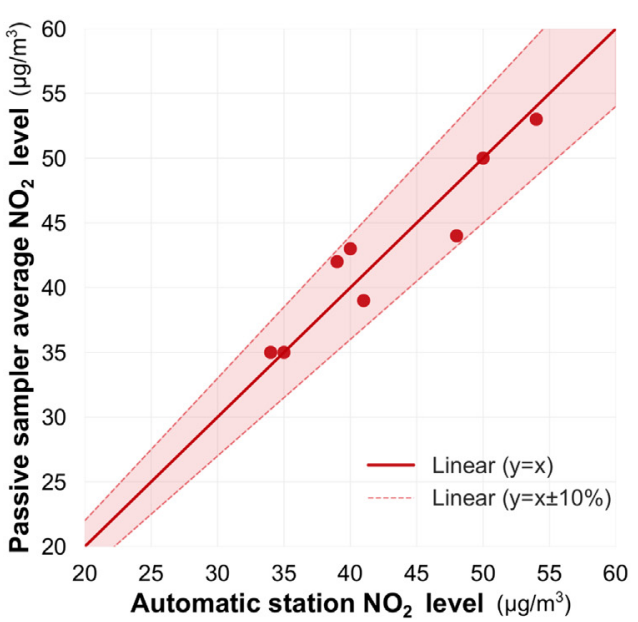

b)

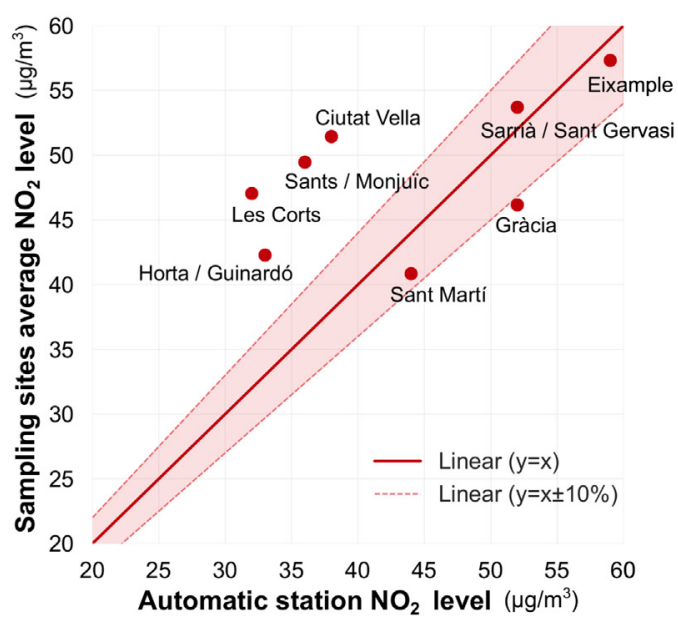

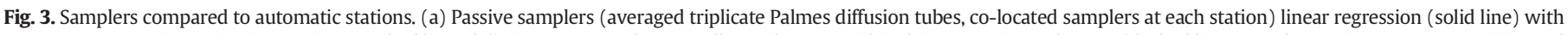

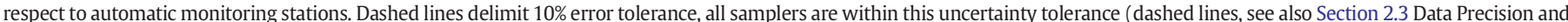

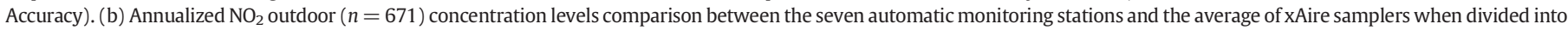

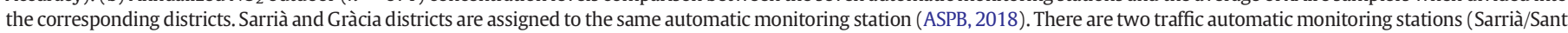
Gervasi or Gràcia and Eixample) and five background automatic monitoring stations (Horta Guinardó, Les Corts, Sants/Montjuïc, Ciutat Vella, Sant Martí). 
a)

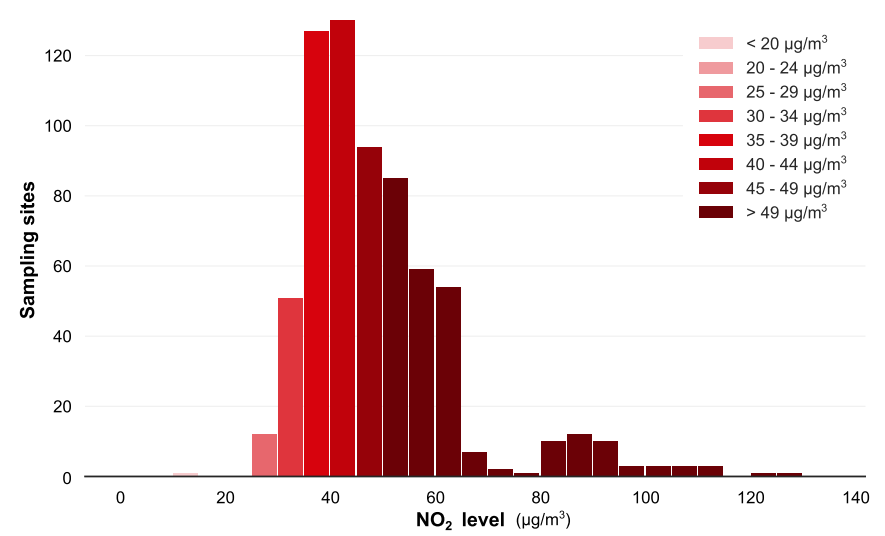

c)

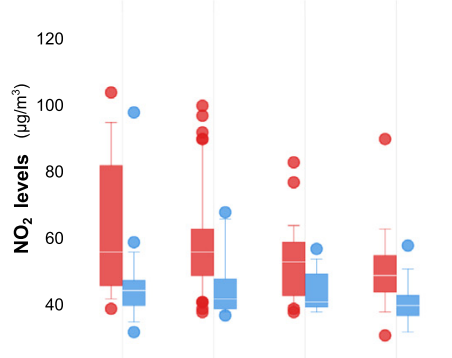

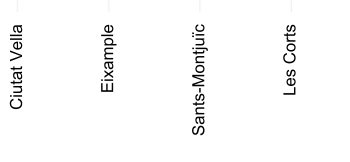

b)

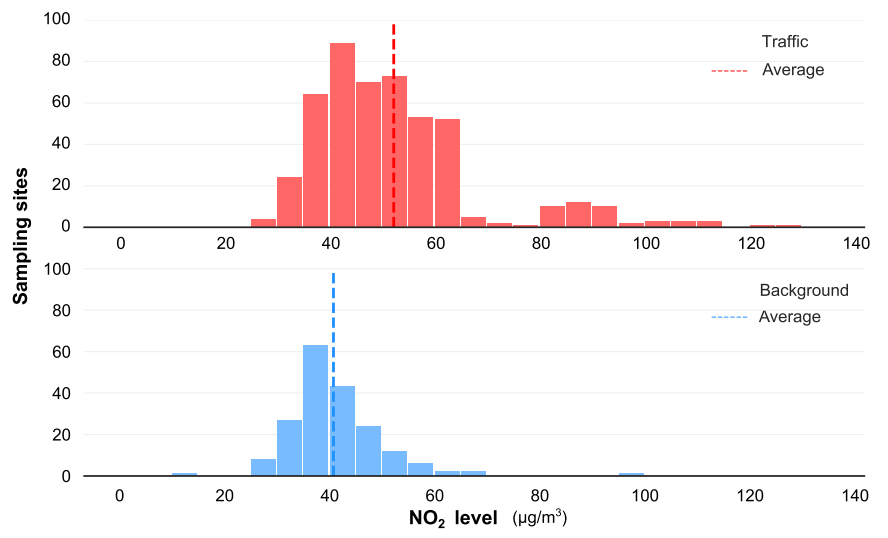

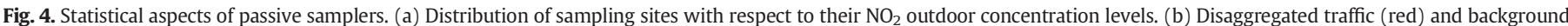

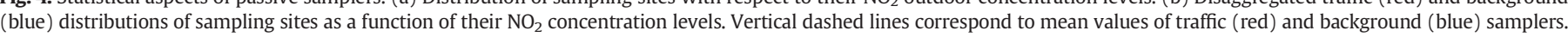

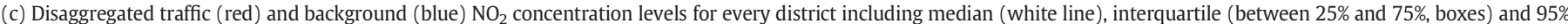
confidence intervals (bars). (For interpretation of the references to color in this figure legend, the reader is referred to the web version of this article.)

school community). Scientific perspective and coordination are being provided only along the protocol guidelines (see Section 2.1 Participatory process). Since xAire aimed to evaluate representativity in terms of air pollution exposure and HIA for Barcelona inhabitants, we thus evaluated the outdoor samplers' spatial distribution and compare it with the population spatial distribution all over Barcelona at the smallest scale available (Barcelona, 2018) (census tract scale, few blocks).

The two-sided Kolmogorov-Smirnov test allows us to state that participant's selection is representative enough to undergo an air pollution exposure analysis (KS test: 0.05 , $p$-value: 0.32 , see Appendix D). The average population per census tract in Barcelona $(n=1068)$ is $1525 \pm 11$ $(\mathrm{SD}=358$ ) while the equivalent one by taking the sampler's location is $1556 \pm 15(\mathrm{SD}=383, n=671)$. Fig. S2 also shows qualitative coincidence among distribution of passive samplers' sites and population distribution in a census tract level. Table S4 provides further statistical insights. Similarly, and at least as a test-bed, we can perform the analysis with the income spatial distribution (INE, 2017) showing a much weaker similarity which leads us to conclude that our sample spatial distribution is not representative of Barcelona income spatial distribution (KS test: 0.11, p-value: 0.0001, Fig. S3(a) and Table S4). If the research aimed to incorporate this economic dimension (Caplin et al., 2019), it would be then necessary to change participatory protocols or to engage alternative or additional communities, in our case evenly distributed communities around public schools across Barcelona and somewhat under-representing wealthier neighborhoods.
Finally, the current analysis also allows the study of the correlation of $\mathrm{NO}_{2}$ concentration levels with population (see Fig. S2(b)) and with income (see Fig. S3(b)). See also Appendix D. Correlations are in both cases small, but income is observed to be more relevant in relation to air quality exposure and, maybe in contrast to other cities, it is positively correlated with income (Caplin et al., 2019).

\subsection{LUR model and health impact assessment}

The best Land Use Regression (LUR) model (Hoek et al., 2008; Ryan and LeMasters, 2007; Cyrys et al., 2012; Eeftens et al., 2012) found includes as covariates: the total traffic flow (total vehicles per day passing through) within $25 \mathrm{~m}$ and $100 \mathrm{~m}$ circular buffer, building density (total terrain surface covered by built area) within $100 \mathrm{~m}$ circular buffer, site type (the sampling location characterization in terms of traffic flows, e.g. traffic or background), the interaction of traffic flow within $25 \mathrm{~m}$ with district sampler location ( $\mathrm{x}$ and $\mathrm{y}$ coordinates, $\mathrm{k}=10$ in Barcelona) and a Generative Additional Model spatial component. The air pollution concentration levels:

$$
\begin{aligned}
\mathrm{NO}_{2} \sim & \text { trafflow }_{25}+\text { trafflow }_{100}+\text { build }_{100}+\text { type }+ \text { trafflow }_{25} \times \text { dist } \\
& +s(x, y, k=10) .
\end{aligned}
$$

The best model performance using the xAire data was found for a scenario with a total of 370 sampling sites after excluding samplers placed within $25 \mathrm{~m}$ from a street intersection or a bus stop and in 
addition to removing all influential observations based on standard Cook's distance. See Section 2.4 Land Use Regression model for further details about the procedure. Model lacks for some relevant covariates which did not improve the model even if forced to be included. It represents a larger number of samplers than in any other previous simultaneous study in Barcelona (Benavides et al., 2019). Adjusted R2 (0.60) and leave-one-out cross-validation R2 (0.55) provided a moderate model performance, a bit lower than most of the models published, which are around 0.70 and 0.80 (Hoek et al., 2008; Ryan and LeMasters, 2007). Participants' sampling selection could explain these small differences. We shall insist that xAire participants were allowed to freely select sampler locations based on their criteria or interest as citizens from a particular neighborhood of Barcelona. Studies focused on air pollution modelling (Ryan and LeMasters, 2007; Hoek et al., 2008) tend to elaborate a more structured selection of sites, ensuring to cover the existing variability range for the different environmental variables within the study area (i.e., elevation, population, land uses but specially for traffic variability).
The number of sites used in the xAire project for LUR modelling are well above the 80 measurement points being used in previous $\mathrm{NO}_{2}$ air pollution exposure (ESCAPE, 2013) and the minimum of sites required $(n=120)$ to obtain a stable and reliable model performance (Basagaña et al., 2012; Johnson et al., 2010). The latter studies have shown that models with a higher number of sampling sites produce a better model performance and less chance of including noisy predictor variables into the model (Basagaña et al., 2012; Johnson et al., 2010).

The xAire data also allowed for an updated and high-resolution picture of health impacts related to $\mathrm{NO}_{2}$ in Barcelona. The model obtained was used to predict the $\mathrm{NO}_{2}$ concentration over a $50 \mathrm{~m}$ point grid in Barcelona. The averaged $\mathrm{NO}_{2}$ concentration at each census tract was eventually calculated (see Fig. 5, Section 2 Material and methods, Fig. S2 and References Rojas-Rueda et al. (2012) and Pierangeli et al., 2020)). Using the WHO guidelines (annual concentration of $40 \mu \mathrm{g} / \mathrm{m}^{3}$ of $\mathrm{NO}_{2}$ (WHO, 2006) as counterfactual exposure, the HIA analysis estimated that 225 cases of asthma in children (1-18 years old), around $9 \%$ of all asthma cases in Barcelona, could be attributed to $\mathrm{NO}_{2}$

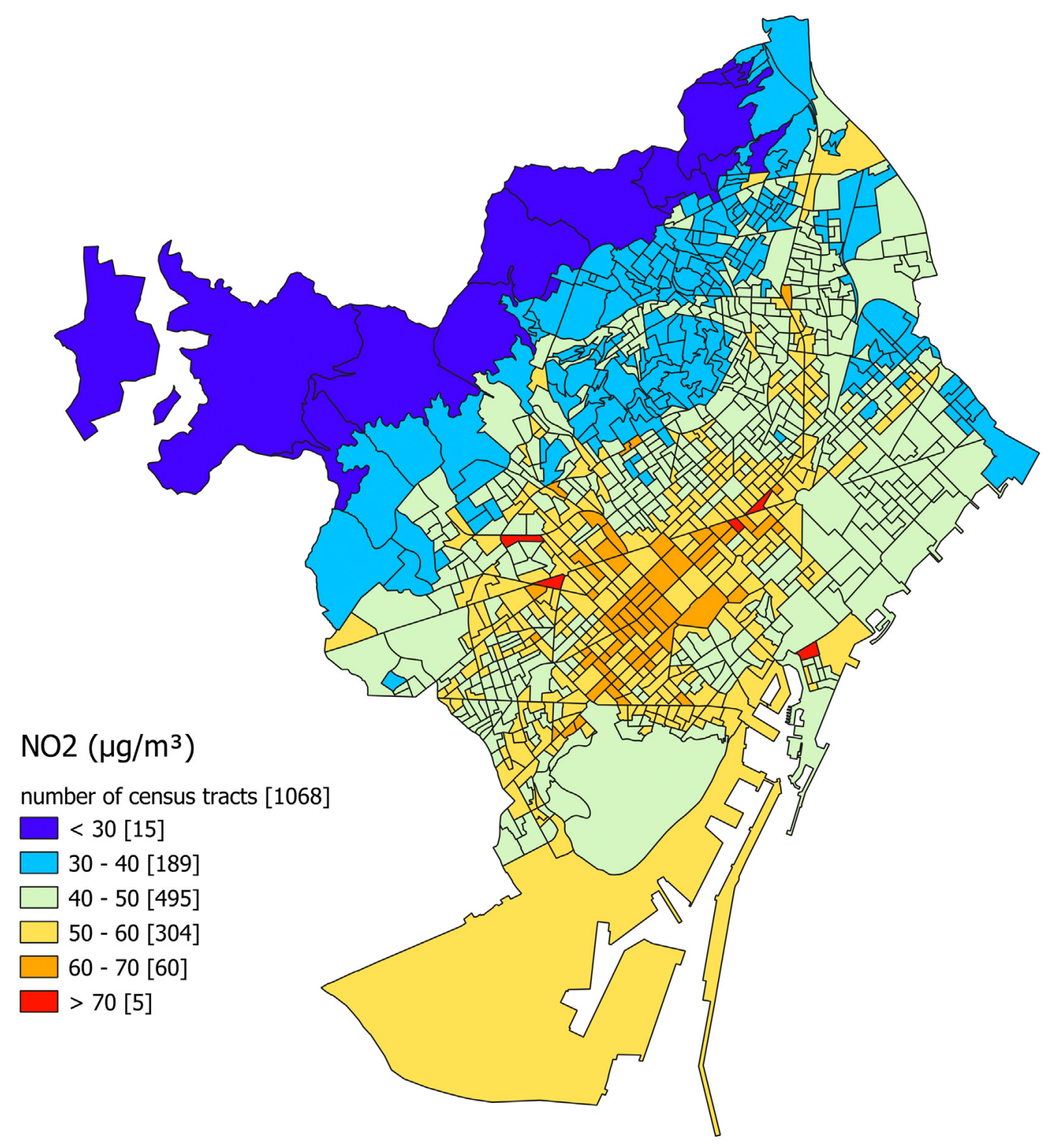

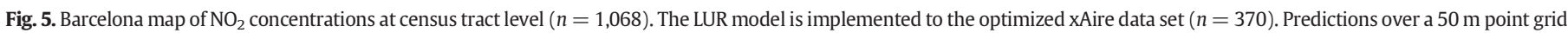
using the LUR model are averaged at census tract level. Color grid varies depending on the $\mathrm{NO}_{2}$ concentration levels. 
concentrations as shown in Table 2. In addition, using a counterfactual exposure of $1.5 \mu \mathrm{g} / \mathrm{m}^{3}$, the HIA analysis estimated 1084 cases of asthma in children could be attributed to $\mathrm{NO}_{2}$ concentrations, $42 \%$ of all asthma cases in Barcelona. These figures also shown in Table 2 are consistent with previous studies estimating asthma related to air pollution in children in Barcelona, which suggested that $48 \%$ of all asthma cases in children could be attributed to $\mathrm{NO}_{2}\left(1.5 \mu \mathrm{g} / \mathrm{m}^{3}\right.$ threshold and for year 2009) (Pierangeli et al. (2020)). Furthermore, it suggests that the current WHO guidelines are not strict enough to prevent many of the annual cases of childhood asthma in Barcelona $(n=859)$.

\subsection{Knowledge and collective action}

After approximately four weeks, the xAire project returned the data to each school group (through teachers and family representatives). All school groups autonomously and independently discussed the $\mathrm{NO}_{2}$ concentration levels in their districts according to the sites selected (with 40 samplers each, inside and around the school, see Section 2.1 Participatory process). The results were mostly discussed in terms of the WHO and EC limit values (WHO, 2006; EEA, 2019) with special attention to those sites far beyond these limits. Table 1 lists the school names jointly with their codename and the student's age and grade. Appendix C provides the details on the context where participants presented the research results.

The discussions demonstrated a clear understanding of the monitoring data and on the process of scientific inquiry: 7-8 year old children were able to perfectly explain the scientific protocol to a regional TV (JM school, InfoK (2018)) or during the Science Congress organised by the Barcelona Education Consortia (e.g. ES school with 11-12 year old children (Consorci2018ES, 2018), and JM school with 7-8 years old children (Consorci2018JM, 2018)). During the official meeting with representatives of the City Council, students pointed to the correlation between air quality and traffic density or between air quality and the lack of green spaces (xAire, 2018): "We had to locate traffic and background spots: we rapidly noticed that we had not many background locations. This means that in our neighborhood (Sant Andreu) there are not enough green areas" or "We located two spots in Avinguda Meridiana since we believed that, there, the nitrogen dioxide levels would be higher than in other places, and we were right" (CF school); "A very clear correlation is observed between air quality and traffic density" or "What contributes most to the poor air quality in our neighborhood is the traffic ring of the city" (at DM school, they retrieved additional data on traffic to support these two statements, see also Reference (Consorci2018DM, 2018)); "Our school is located in a touristic area, where theres is a lot of traffic, both cars, buses and coaches. This explains that in some of the locations we have obtained values greater

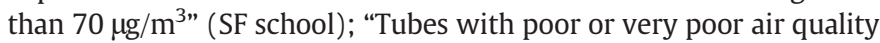
are the ones on the busiest streets and with a large number of vehicles" (TB school), "We observe that locations close to Passeig de la Zona Franca and Ildefons Cerdà square show high levels of nitrogen dioxide because there is a high traffic density" (SE school, Reference (Consorci2018SE, 2018)).

Since the diffusion tubes were often located in the home-to-school path (Consorci2018ES, 2018; Consorci2018SF, 2018), the results were relevant to students, and they were able to make a diagnosis on their own with no professional scientific supervision and noticed that "it was not easy to find a non-polluted pedestrian path to go to school"
(ES school, Reference (Consorci2018ES, 2018)). EH school studied the difference in $\mathrm{NO}_{2}$ levels: "Larger streets showed higher levels due to the high traffic density" (Consorci2018EH, 2018). Observations were also made regarding green areas (xAire, 2018): "Air quality was qualified as 'very good' only in a little park surrounded by buildings." (SM school); "In the fewest green areas we have in the neighborhood, the air quality is qualified as 'poor' or 'moderate"' (SF school). The results also generated surprise (xAire, 2018): "This data tell us we are exposed to a 'moderate' level of pollution, which, given where our school is located, we expected a better rate" (AG school); "Most of us think that it is a neighborhood where there are many parks and with the Superilla the air should be cleaner." (SM school, Superilla/superblock is an urban intervention that reduces motorized vehicles).

The students indeed reported that the data collection process enhanced their connection to place and awareness about air pollution exposure in their school and district while considering possible effects in health and well-being (Consorci2018SF, 2018; Consorci2018EH, 2018). Results explicitly generated concern when related to health (xAire, 2018): "Only one tube showed a good air quality" (PC school, Reference (Consorci2018PC, 2018)); "We have an average of $50 \mu \mathrm{g}$ per cubic meter and this makes Ciutat Vella district the second district most polluted in Barcelona. Very sad news for us!" (CE school); "Our school is surrounded by three highly polluted streets which we also have found to be those with more dense traffic" (ES school, the school measured the traffic flow on their own, Reference (Consorci2018ES, 2018)); "The air quality in front of the school is "very poor" (JM school)"; "In our playground the air quality is qualified as 'moderate' and 'poor', that is the reason why we are very worried" (SF school); "We find it very worrying that the air we breathe when we are doing Physical Education or when we are playing at the playground. The air is unhealthy where we do outdoor activities at our school and where we do extracurricular activities. [...] We are especially concerned about our younger teammates because they are breathing polluted air when they are at the playground." (LC school). The students correlated the results with health impacts (xAire, 2018): "Not having good air quality implies: more respiratory diseases, interferences in the cognitive development of school-aged children" (AG school). They also demanded public authorities to take some action (xAire, 2018): "The air quality we breathe in our district is poor. And we believe that it is very necessary to look for urgent solutions to this problem." (SF school); "The average level in our district is $45 \mu \mathrm{g}$ per cubic meter, which implies that the air quality is poor. This is worrying us and we hope you can take some action" (CF school); "We ask you as policymakers to consider the action plans we propose with the aim to improve our health and the health of our city" (JM school).

The measures proposed by the young students during the event with public authorities ranged from the promotion of use and (economic) accessibility of public transport in the neighborhood (DM, JM, AG, and SE schools (xAire, 2018), and also TB school, Reference (Consorci2018TB, 2018)), the promotion of pedestrian routes (JM, AG, SE, and AB schools, xAire (2018)), a substantial increase of green areas and pedestrian streets (ES, CF, JM, LC, and SE schools, References (Consorci2018ES, 2018; Consorci2018CF, 2018; xAire, 2018)), installing parking lots to persuade commuters to not enter to Barcelona with private cars (DM school, xAire (2018)), covering the ring road (DM school, xAire (2018) and Reference (Consorci2018DM, 2018)), limiting car circulation or shifting from combustion to electric vehicles (DM, JM, AG, AB and FP

Table 2

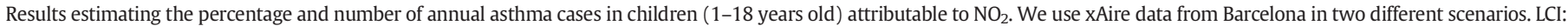
Lower confidence interval of asthma cases; UCI: Upper confidence interval of asthma cases.

\begin{tabular}{|c|c|c|c|c|}
\hline & $\%$ & Asthma cases & $\mathrm{LCI}$ & UCI \\
\hline Scenario 1: comparing with WHO guidelines $\left(40 \mu \mathrm{g} / \mathrm{m}^{3}\right)$ & 9 & 225 & 96 & 302 \\
\hline Scenario 2: comparing with minimum reported levels $\left(1.5 \mu \mathrm{g} / \mathrm{m}^{3}\right)$ & 42 & 1,084 & 515 & 1,364 \\
\hline
\end{tabular}


schools, xAire (2018), Reference (Consorci2018FP, 2018)), or promoting the use of bikes and electric scooters with new lanes (DM, SE, AG schools), xAire (2018); and TB school, Reference (Consorci2018TB, 2018).

Furthermore, families' engagement - who received training, collaborated in the planning and implementation of the samplers' location was excellent. Large numbers of families showed willingness to come to an evening training session, which turned into a general assembly to agree on a shared protocol (see Section 2.1 Participatory process). They also collaborated in the decision-making process of the places where samplers were installed, in the deployment and removal of the samplers, and in several events to promote change based on data collected. A mother from SF school said "I've always been very involved in school. I did not hesitate to be part of the project and also learn about air quality sensors" ARA (2018). The supportive engagement of students' parents and relatives points to how environmental awareness and advocacy could be diffused through peers and social networks (Johnson et al., 2014). SF school evaluated the activity during their presentation in front of the public authorities, describing xAire as: "a fun activity. [...] We learned a lot of different things and it helped us get to know the neighborhood better" (xAire, 2018). Beyond scientific skills, the teachers agreed that the xAire project helped the students see the social value of the knowledge produced within the class group. A teacher from JM school explained that "when kids see that behind an activity there is a reason and an intention, they feel fulfilled" (ARA, 2018) and another teacher from SF school stated: "They are at an age that all excites them, they are very receptive, they cheer up right away. I am convinced that they will never forget this experience" (ARA, 2018). The teacher from SF also stated that "it has [also] been a stimulus for her. If the teacher is motivated the students too." (ARA, 2018). She also admitted that although "[It] was an intense work at the team level, they generated digital skills and, above all, they are now very aware after learning about how air quality affects their health and their learning performance. Such intense experiences, also have an effect inside families" (ARA, 2018).

Most of the schools took further action beyond data collection and discussion within the xAire planned activities and disseminated their results in a number of local events and in front of a variety of audiences (see Appendix C). The SF group came together with their families (more than 40 people) and teachers to actively participate in the Barcelona Science Festival and autonomously presented the results of the research to the public. Another school group of about 20 students (SM) arranged the presentation of their results in front of an adult audience at the Barcelona Mobile Week, which triggered a vivid debate in the audience that continued on Twitter afterwards about the benefits and pitfalls of the Superilla urban intervention in the district. ES and TB schools started a local campaign with families and neighbors (Consorci2018ES, 2018; Consorci2018TB, 2018). ES school submitted a formal petition to remove traffic in a central and congested street in the district (Av. Meridiana) and surrounding area, and finally presented the results in front of the Mayor at the opening of the Science Congress and directly asked her to immediately start the major works already planned to reduce traffic and increase the amount of green space (Consorci2018ES, 2018). CF school, based on their concern on air quality, decided to introduce plants inside classrooms through a new research project (Consorci2018CF, 2018), TB school chose new or modified the plant species in their garden by considering their capacity to absorb pollution (Consorci2018TB, 2018), and SF and TB schools started to construct vertical gardens in their school playground (Consorci2018SF, 2018; Consorci2018TB, 2018).

\section{Discussion}

This paper describes the experience of a large-scale and unprecedented citizen science monitoring campaign in Barcelona (Spain) with $\mathrm{NO}_{2}$ passive Palmes diffusion tubes (EEA, 2019; Palmes et al., 1976). Eighteen primary schools evenly distributed in the 10 city districts and 1,650 participants (7-12 years old children, their families and teachers) deployed 725 samplers across Barcelona (671 outdoor samplers, 31 in playground and 23 inside school buildings), selecting their locations and autonomously interpreting their $\mathrm{NO}_{2}$ concentration levels. We have reported the multifaceted outcomes of the xAire project to support the broad statement that citizen science can contribute to air quality monitoring in its interplay between advances in environmental exposure assessment and developments in policy (Caplin et al., 2019; Haklay, 2015; Fritz et al., 2019; EEA, 2019; De Craemer et al., 2020; Sauermann et al., 2020). We further assess the health impacts that air pollution levels have in the city. The xAire project is an example of how a broad partnership is able to enhance community (and individual) knowledge and attitudes towards city-level collective response to air pollution exposure (Schaefer et al., 2020; Golumbic et al., 2019; Mahajan et al., 2020).

xAire used Palmes' diffusion tubes. Palmes sampler consists of an acrylic tube $7.1 \mathrm{~cm}$ long and $1.1 \mathrm{~cm}$ internal diameter and they can be hung at selected locations. Palmes tubes are thus simple, cheaper than other low-cost sensors, easy to use, ideal to be deployed in large numbers over a wide area and thus providing good spatial coverage (EEA, 2019b; Hafkenscheid et al., 2009). Palmes tubes also comply with the data quality objectives (e.g., EU/WHO standards) and they are comparable to long-term limit values like annual average (De Craemer et al., 2020), a key and easy-to-understand value both for citizens and public bodies (EEA, 2019b). All these characteristics make Palmes tubes the most attractive low-cost sensor choice for citizen science initiatives such as xAire which do not need real-time data (Haklay and Eleta, 2019; De Craemer et al., 2020). Palmes tubes and the pop-up and nonpermanent nature of the xAire citizen science campaign also allows to circumvent challenges that other low-cost sensors need to face. As other low-cost generally look for a long-term deployment, they thus need to cover costs and staffing requirements to maintain, repair, and replace monitoring equipment (see also an interesting discussion in Wong et al. (2018)).

In any case, there is already a large number of opportunities for highresolution measurements of air pollutants in cities (Dutta et al., 2009; Kumar et al., 2015; Clements et al., 2017; Castell et al., 2017; Jerrett et al., 2017; Mijling et al., 2018; Ripoll et al., 2019; Languille et al., 2020). Due to the increasing evidence of adverse health effects, the related technological and scientific efforts need to be accompanied by actionable insights that harness policies, recommendations and collective actions both at a city level and at a high-resolution (neighborhood, census tract) level (Caplin et al., 2019). However, public support for policies might be jeopardized due to the public perception of lack of information or the unsatisfied desire of citizens to express their own views on air quality issues (Eurobarometer, 2019). Therefore, it seems necessary that rigorous and robust scientific methodologies offer citizens an active role in the scientific research process. Citizen science practices, broadly defined as the participation of the public in research (Heigl et al., 2019; Auerbach et al., 2019), can offer this space.

In xAire, communities (class groups jointly with families and teachers) have successfully delivered reliable data following a shared protocol that was jointly agreed, and co-designed in a preliminary testing phase which was built upon previous experiences (Haklay and Eleta, 2019). The distribution of $\mathrm{NO}_{2}$ concentration levels reported was ample and revealed high to very high levels ( $5 \%$ of the samplers, $n=34$, show levels higher than $86 \mu \mathrm{g} / \mathrm{m}^{3}$ ), thus confirming that air quality is a serious issue throughout Barcelona, also at a high-resolution level. Extending participation by selecting the sites and by informing and autonomously interpreting the results obtained might indeed explain the high quality of the data (high success ratio in sample deployment and with satisfactory meta-data) which circumvents the risk of low-quality data due to the fact that non-experts may report less information than experts (Benedetti et al., 2018).

Participatory processes also have the risk of a lack of representativeness in the distribution of samplers at a city level. Representativeness is 
a key discussion in biodiversity monitoring with citizen science practices. Some articles have already highlighted the need to statistically handle biases (Kosmala et al., 2016) of spatial data due to particular amateur preferences for species and habitats (Tiago et al., 2017; Kallimanis et al., 2017). In some experiences, citizen science monitoring is then reduced to a complementary support to the ongoing conservation management efforts (Dumas et al., 2020). Unfortunately, there is still no systematic agreement about how to deal with these issues in air quality citizen science campaigns. Wong et al. (2018) have already shown that, by engaging community residents in the monitor siting processes, the resulting air monitoring network data are relevant, trusted, understandable, and used by community residents. Integration of spatial analysis and air monitoring best practices into the network development process ensures that the data are reliable and appropriate for use in research activities. xAire considered representativeness in terms of population spatial distribution as the project was oriented to health impact evaluation. Spatial population distribution of xAire sampling in a census tract level has been shown to be consistent with city spatial population distribution but it has shown inconsistencies with inhabitants' income spatial distribution. Participatory design process (recruitment and research protocol) thus necessarily needs to be reconsidered if a different research question is posed.

The air quality map generated by xAire represents an invaluable tool to estimate current exposures to $\mathrm{NO}_{2}$ in Barcelona: it used an increased number of measurement sites compared to previous models with samplers distributed by professional scientists, and an updated (and therefore more realistic) set of concentration levels. To conduct the HIA for asthma cases, we developed the LUR model (Ryan and LeMasters, 2007; Hoek et al., 2008; Cyrys et al., 2012; Eeftens et al., 2012) with 371 sites out of the 671 samplers deployed by citizens. The larger number of locations (typically between 40 and 80 ) jointly with the fact that it is possible to consider citizens site selection into the LUR model can be considered as relevant and novel contributions to previous publications that map $\mathrm{NO}_{2}$ concentration with LUR models. This number (the 371 sites) can be understood as a minimal necessary number to obtain a complete picture of Barcelona, and greatly extends previous measurements (Benavides et al., 2019; Basagaña et al., 2012; Johnson et al., 2010; ESCAPE, 2013). The study shows that methods to effectively integrate citizen science contributions in these land use regression methods are urgently needed (Wong et al., 2018), in the same way as new methods have been recently demanded in the context of air quality compliance and policy support (De Craemer et al., 2020). Furthermore, at a practical level, the estimate of childhood asthma cases attributable to $\mathrm{NO}_{2}$ concentrations (in terms of percentage) in a census tract level provided by our citizen science approach is found to be statistically consistent with previous contributions in the literature (Khreis et al., 2017). It also shows the large impact that air pollution still has in the city, with more than a 1,000 new cases of childhood asthma in the city each year. The result also encourages the implementation of large-scale air quality citizen science campaigns in those cities that lack automatic monitoring systems (Haklay and Eleta, 2019; West et al., 2020). All these different outcomes reinforce the idea that citizen science practices can effectively contribute to environmental exposure assessments and policy.

Perceptions are an important component of behavior change and shape public response to environmental management (Stern, 2000). Governments are grappling with how to empower citizens to be involved in various aspects of environmental management (Biolnnovation Service, 2018; USEPA, 2016; EEA, 2019b). While acknowledging the potential of community and individual level interventions for reducing exposure to air pollution and improving public health, citizen participation in data collection and environmental monitoring can play a major role in increasing environmental awareness by improving peoples' perceptions of exposure and risk for individual acceptance and action (Jordan et al., 2019; Haywood et al., 2016; Johnson et al., 2014).

Overall, participation in crowd-sourced collection of air pollution exposure can therefore contribute to promote knowledge and understanding of the practice of science (Bonney et al., 2016) and relevance of scientific outcomes, but also improve environmental awareness and advocacy (Jordan et al., 2019; Haywood et al., 2016; Johnson et al., 2014).

\section{Conclusions}

Large-scale air quality citizen science campaigns should not be simply seen as a public awareness (or a science dissemination) activity and a hands-on education programme (Perelló et al., 2017). Lower intensity level of participation is extremely valuable and might be seen as sufficient by professional scientists to engage citizens, but it does not guarantee per se a rigorous collection of high-resolution and representative air quality data nor an improvement in current air quality exposure maps, LUR models or health impacts. With a more intense participatory component, such as research co-design (Senabre et al., 2018), participants can anticipate benefits which in turn are organically incorporated in the project design.

This citizen science approach adds sophistication to the scientific research process as it requires multidisciplinary professional scientists and the involvement of non-academic organisations, such as school networks (see also the recent Clean@Schools (Mineco, 2020) experience) and is not limited to public agencies. Public presentations showed that the xAire project has substantially increased the students' (aged between 7 and 12 years old) and their families' knowledge and understanding of air quality measurements. Participants were also able to evaluate the relation of motor vehicles and internal combustion engine emission with $\mathrm{NO}_{2}$.

Through placed-based learning (Haywood et al., 2016; Perelló et al., 2017) and the use of scientific standards and methods as a means of verification (Kullenberg, 2015), citizen science has proven to contribute to improved risk identification, problem-solving (Berti Suman and van Geenhuizen, 2019), environmental stewardship (Jordan et al., 2019), advocacy (Johnson et al., 2014) and conservation action (Haywood et al., 2016). Active citizen support and new forms of communication among experts and citizens and the involvement of all major stakeholders are crucial to find and successfully implement health promoting policy measures.

Supplementary data to this article can be found online at https://doi. org/10.1016/j.scitotenv.2021.147750.

\section{Data availability}

Data in Brief (submitted). MethodsX (submitted).

\section{Funding}

This work was partially supported by MINEICO (Spain), Agencia Estatal de Investigación (AEI) and Fondo Europeo de Desarrollo Regional (FEDER) [grant number: FIS2016-78904-C3-2-P, JP, AC, JV, and IB; grant number: PID2019-106811GB-C33, JP, AC and IB]; by Generalitat de Catalunya (Spain) through Complexity Lab Barcelona [grant number: 2017 SGR 608; JP, AC, JV, IB]; by European Union Horizon 2020 research and innovation programme (CoAct) [grant number: 873048; JP, AC, IB]; by COST Action (European Cooperation in Science and Technology) [grant number; CA15212]; by Institut de Cultura de Barcelona; by Mobile World Capital; and by DKV Salud.

\section{CRediT authorship contribution statement}

Josep Perelló: Conceptualization, Methodology, Validation, Formal analysis, Investigation, Resources, Data curation, Writing - original draft, Writing - review \& editing, Visualization, Supervision, Project administration. Anna Cigarini: Methodology, Writing - original draft, Investigation, Data curation, Writing - review \& editing. Julián Vicens: 
Methodology, Software, Formal analysis, Visualization, Data curation, Writing - review \& editing. Isabelle Bonhoure: Writing - original draft, Investigation, Data curation, Writing - review \& editing. David Rojas-Rueda: Investigation, Formal analysis, Writing - review \& editing. Mark J. Nieuwenhuijsen: Investigation, Formal analysis, Writing - review \& editing. Marta Cirach: Methodology, Software, Formal analysis, Visualization, Data curation, Writing - original draft, Writing - review \& editing. Carolyn Daher: Resources, Data curation, Writing - review \& editing, Project administration. Jaume Targa: Methodology, Formal analysis, Resources, Data curation, Writing - original draft, Writing - review \& editing, Project administration. Anna Ripoll: Methodology, Formal analysis, Visualization, Data curation, Writing - original draft, Writing - review \& editing.

\section{Declaration of competing interest}

The authors declare that they have no known competing financial interests or personal relationships that could have appeared to influence the work reported in this paper.

\section{Acknowledgements}

We acknowledge the participation of more than 1,650 volunteers (families and teachers) who made this research possible and that belong to the community of the public primary schools: Escola Els Horts (Sant Martí district), Escola Sant Martí (Sant Martí), Escola El Sagrer (Sant Andreu), Escola Can Fabra (Sant Andreu), Escola Calderón (Nou Barris), Escola Timbaler del Bruc (Nou Barris), Escola Pau-Casals Gràcia (Gràcia), Escola Sagrada Família (Gràcia), Escola Joan Miró (L'Eixample), Escola Fort Pienc (L'Eixample), Escola Dolors Monserdà Santa Pau (Sarrià-Sant Gervasi), Escola Seat (Sants-Montjuïc), Escola Àngels Garriga (Horta-Guinardó), Escola Coves d'en Cimany (Horta-Guinardó), Escola Àngel Baixeras (Ciutat Vella), Escola Cervantes (Ciutat Vella), Escola Lavínia (Les Corts), and Escola Les Corts (Les Corts). We also thank Amanda Masha-Caminals for her crucial support and logistics jointly with the active participation of the rest of the CCCB team (specially Rosa Ferré, Elisenda Poch and José Luis de Vicente); the Consorci d'Educació de Barcelona team for their strong commitment to xAire and City Station; Marta Pahissa and DKV Salud for considering the xAire project as part of their mission; Maria Alonso and Louise Francis from Mapping for Change for the active collaboration sharing thoughts, protocols and their digital platform; Rosa Arredondo and the Mobile World Capital team for their confidence in the xAire project; and the Barcelona City Council for their interest and commitment to xAire and City Station.

\section{Appendix A. Context}

The xAire project was conceived within the City Station participative community-based project as part of the "After The End of The World" exhibition at the Centre de Cultura Contemporània de Barcelona (October 2017 to May 2018), and built with the artist and engineer Natalie Jeremijenko. The exhibition was devoted to climate change with a highly experiential mode. As part of the exhibition, City Station was a public space and infrastructure to enable several actions for improving environmental health in a participatory manner (November 2017 to April 2018). City Station was placed in a community space (Passatge Trullàs, Barcelona) in collaboration with the Barcelona City Council and the Taula Eix Pere Quart (civil society organisation). City Station was conceived as a citizen platform that, with the support of a broad list of scientific research groups and united the effort of neighbors, collectives, cooperatives of the Poblenou neighborhood.

\section{Appendix B. Preliminary test}

During discussions with groups of citizens and several scientific research groups at City Station (see Appendix A), the decision was taken to conduct air quality measurements due to the lack of air quality information for the general public in specific points in the city, but also due to the lack of extensive high-resolution scientific studies in Barcelona. In order to gain practical experience in participatory air quality monitoring, and inspired by the experience of Mapping for Change in London (Haklay and Eleta, 2019), as part of a COST Action programme grant, some of the authors and a group of about 40 neighbors jointly designed first protocol while installing 40 passive diffusion tubes samplers in the Poblenou neighborhood. Special attention was given to locate the tubes inside and outside of a Superilla area (superblocks) where, not without public controversy, the municipality had recently pacified motorized vehicles (air quality samplers' installation: November 12th, 2017; removal: December 15th 2017). Based on the pilot, revisions were made to the protocol that was then presented to the schools in the participatory process. For example, in the pilot phase, several tubes were placed at bus stops, but all of these tubes were removed, so this sampling location was excluded in the revised protocol.

\section{Appendix C. Public presentations}

Campaigns were extensively covered by local media (newspapers, agencies, and local and regional TV). Students and their teachers presented with no mediation the results in front of journalists (e.g., JM and PC schools) with no mediation. The second public presentation was during the annual Science Congress (May 22-24th, 2018) organised by the CEB for public primary schools from Barcelona to meet and share their research on a numerous set of topics related to sustainability. Their contributions were recorded and are publicly accessible on the congress website (Congres, 2018) with YouTube streaming. Eleven schools involved in the xAire project further requested an official meeting with local administration representatives to share their results. The leaders of the xAire project facilitated the organisation of a joint visit to the city council (Saló de Cent, April 26th, 2018 as reported in the Barcelona City Council (Ajuntament de Barcelona, 2018b)). Approximately 200 students (between 7 and 12 years old), families and teachers were received by the Deputy Mayor in Ecology, Urbanism and Mobility, and the Commissioner of Ecology. During a 1h30m session, 22 student representatives (two per each school) presented their own investigations, formally delivered the results to the city and demanded specific actions from local authorities. For this event, each school drafted a final report that was given to the Deputy Mayor and the Commissioner (xAire, 2018). In addition, the SF school group came together with their families (more than 40 people) and teachers to actively participate in the Barcelona Science Festival (June 9th, 2018). Another school group of about 20 students (SM) arranged the presentation of their results in front of an adult audience at the Mobile Week (February 20th, 2018, within the Barcelona Mobile World Congress programme).

\section{Appendix D. Kolmogorov-Smirnov test and Pearson correlation}

The representativity of the xAire samples regarding income and population in Barcelona were analyzed by means of a two-sided Kolmogorov-Smirnov test in order to know if both samples were drawn from the same continuous distribution. We reject the null hypothesis if $p$-value is lower than 0.05 , meaning that the independent samples are not drawn from the same continuous distribution. Linear correlation between $\mathrm{NO}_{2}$ levels and, income and population distribution respectively, was tested by means of Pearson's correlation coefficient. Results are shown in Figs. S2 and S3 while additional features are provided in Table S4.

\section{References}

Agència de Salut Pública de Barcelona, 2018. Avaluació de la Qualitat de l’Aire a la Ciutat de Barcelona. Informe 2017. 
Ajuntament de Barcelona, 2014. Aranya de carrers de Barcelona. [Map]. Departament de Mobilitat, Ajuntament de Barcelona.

Ajuntament de Barcelona, 2018a. Dades bàsiques de mobilitat. Informe 2017.

Ajuntament de Barcelona (2018b, 26 April). Barcelona schoolchildren gather data on the city's air quality https://ciutatrefugi.barcelona/en/noticia/barcelona-schoolchildrengather-data-on-the-citys-air-quality_647956 [Accessed: March 9, 2020].

ARA 2018. Vallejo, O. (2018, 29 Oct) xAire mesura la qualitat de l'aire. Diari ARA. Suplement Criatures. https://criatures.ara.cat/escola/Xaire-mesura-qualitat-aireprojecte-escoles_0_2097390254.html [Accessed: March 9, 2020].

Auerbach, J., Barthelmess, E.L., Cavalier, D., Cooper, C.B., Fenyk, H., Haklay, M., Shanley, L., 2019. The problem with delineating narrow criteria for citizen science. Proc. Natl. Acad. Sci. 116 (31), 15336-15337.

Basagaña, X., Rivera, M., Aguilera, I., Agis, D., Bouso, L., Elosua, R., Künzli, N., 2012. Effect of the number of measurement sites on land use regression models in estimating local air pollution. Atmos. Environ. 54, 634-642.

Benavides, J., Snyder, M., Guevara, M., Soret, A., García-Pando, C.P., Amato, F., Jorba, O., 2019. CALIOPE-urban v1. 0: coupling R-LINE with a mesoscale air quality modelling system for urban air quality forecasts over Barcelona city (Spain). Geosci. Model Dev. 12 (7), 2811-2835

Benedetti, Y., Slezak, K., Møller, A.P., Morelli, F., Tryjanowski, P., 2018. Number of syllables in cuckoo Cuculus canorus calls: a test using a citizen science project. Sci. Rep. 8 (1), 12872.

Berti Suman, A., van Geenhuizen, M., 2019. Not just noise monitoring: rethinking citizen sensing for risk-related problem-solving. J. Environ. Plan. Manag. 1-22.

BioInnovation Service. (2018). Citizen science for environmental policy: development of an EU-wide inventory and analysis of selected practices. Final report for the European Commission, DG Environment under the contract 070203/2017/768879/ ETU/ENV.A.3, in collaboration with Fundacion Ibercivis and The Natural History Museum, November 2018.

Bonney, R., Phillips, T.B., Ballard, H.L., Enck, J.W., 2016. Can citizen science enhance public understanding of science? Public Underst. Sci. 25 (1), 2-16.

Borge, R., Lumbreras, J., Pérez, J., de la Paz, D., Vedrenne, M., de Andrés, J.M., Rodríguez, M.E., 2014. Emission inventories and modeling requirements for the development of air quality plans. Application to Madrid (Spain). Sci. Total Environ. 466, 809-819.

Caplin, A., Ghandehari, M., Lim, C. Glimcher, P. Thurston, G, 2019. Advancing environmental exposure assessment science to benefit society. Nat. Commun. 10 (1), 1236.

Carslaw, D.C., 2005. Evidence of an increasing $\mathrm{NO}_{2} / \mathrm{NOx}$ emissions ratio from road traffic emissions. Atmos. Environ. 39 (26), 4793-4802.

Castell, N., Kobernus, M., Liu, H.Y., Schneider, P., Lahoz, W., Berre, A.J., Noll, J., 2015. Mobile technologies and services for environmental monitoring: the citi-sense-MOB approach. Urban Clim. 14, 370-382.

Castell, N., Dauge, F.R., Schneider, P., Vogt, M., Lerner, U., Fishbain, B., Bartonova, A., 2017. Can commercial low-cost sensor platforms contribute to air quality monitoring and exposure estimates? Environ. Int. 99, 293-302.

Chen, L.J., Ho, Y.H., Lee, H.C., Wu, H.C., Liu, H.M., Hsieh, H.H., Lung S.C.C., 2017. An open framework for participatory PM2. 5 monitoring in smart cities. IEEE Access 5, 14441-14454.

Clements, A.L., Griswold, W.G., Rs, A., Johnston, J.E., Herting, M.M., Thorson, J., Hannigan, M., 2017. Low-cost air quality monitoring tools: from research to practice (a workshop summary). Sensors 17 (11), 2478.

Congres 2018. Website of the Science Congress (Congrés de Ciència, in Catalan) https:// sites.google.com/site/5econgresstreaming [Accessed: July 28, 2020].

Consorci2018CF. Consorci d'Educació de Barcelona (2018, 23 May). Streaming recording of kids' presentations in 5th Science Congress (in Catalan) Escola Can Fabra https:// youtu.be/_F9dz2XG0GQ [Accessed: July 28, 2020]

Consorci2018DM. Consorci d'Educació de Barcelona (2018, 22 May). Com evolucionaria un ecosistema en equilibri ecològic per l'augment de la temperatura del planeta? Streaming recording of kids' Presentations in 5th Science Congress (in Catalan). Escola Dolors Monserdà Santa Pau. https://youtu.be/piYM6wv2v04 [Accessed: July $28,2020]$.

Consorci2018EH. Consorci d'Educació de Barcelona (2018, 24 May). Com podem saber si la qualitat de l'aire que respirem al nostre barri és bona? Streaming recording of kids' Presentations in 5th Science Congress (in Catalan) Escola Els Horts https://youtu.be/ gXNXgYWQ3TU [Accessed: July 28, 2020].

Consorci2018ES. Consorci d'Educació de Barcelona (2018, 22 May). Com afecta el trànsit a la qualitat de l'aire que ens envolta? Streaming recording of kids' Presentations in 5th Science Congress (in Catalan). Escola El Sagrer. https://youtu.be/4FByPK3QKA0 [Accessed: July 28, 2020].

Consorci2018FP. Consorci d'Educació de Barcelona (2018, 24 May). Com és que l'Ajuntament de Bcn vol limitar la circulació d'alguns vehicles dins de la ciutat durant alguns dies concrets? Streaming recording of kids' Presentations in 5th Science Congress (in Catalan) Escola Fort Pienc https://youtu.be/3aNKTrwONF0 [Accessed: July $28,2020]$.

Consorci2018JM. Consorci d'Educació de Barcelona (2018, 23 May) Per què des del Tibidabo a vegades no veiem el mar? Streaming recording of kids' presentations in 5th science congress (in Catalan). Escola Joan Miró. https://youtu.be/NdllbLYxdFs [Accessed: July 28, 2020].

Consorci2018PC. Consorci d'Educació de Barcelona (2018, 23 May). Streaming recording of kids' presentations in 5th Science Congress (In Catalan) Escola Pau Casals Gràcia https://youtu.be/0b4FO2QRoZQ [Accessed: July 28, 2020]

Consorci2018SE. Consorci d'Educació de Barcelona (2018, 24 May). Com és l'aire que respirem al nostre barri? Streaming recording of kids' Presentations in 5th Science Congress (in Catalan) Escola SEAT https://youtu.be/B60crEVfpXc [Accessed: July 28, 2020]

Consorci2018SF. Consorci d'Educació de Barcelona (2018, 24 May). Com és l'aire que respirem en els nostres camins a l'escola? (Estudi de la concentració de diòxid de nitrogen al nostre barri). Streaming Recording of kids' Presentations in 5th Science Congress (in Catalan) Escola Sagrada Família. https://youtu.be/j6gTkHHq_C4 [Accessed: July 28, 2020].

Consorci2018TB. Consorci d'Educació de Barcelona (2018, 24 May). Com podem millora la qualitat de l'aire a la nostra escola? Streaming recording of kids' Presentations in 5th Science Congress (in Catalan) Escola Timbaler del Bruc https://youtu.be/ P2BEymW-QNQ [Accessed: July 28, 2020].

Cyrys, J., Eeftens, M., Heinrich, J., Ampe, C., Armengaud, A., Beelen, R., Cirach, M., 2012. Variation of $\mathrm{NO}_{2}$ and $\mathrm{NOx}$ concentrations between and within 36 European study areas: results from the ESCAPE study. Atmos. Environ. 62, 374-390.

De Craemer, S., Vercauteren, J., Fierens, F., Lefebvre, W., Meysman, F.J., 2020. Using LargeScale NO2 Data from Citizen Science for Air-Quality Compliance and Policy Support. Environmental Science \& Technology 54 (18), 11070-11078.

Digital Elevation Model for Catalunya [DEM]. 2021 Institut Cartogràfic de Catalunya (ICC).

Directive 2008/50/EC of the European Parliament and of the Council of 21 May 2008 on ambient air quality and cleaner air for Europe OJ L 152, 11.6.2008, p. 1-44.

Dumas, P., Fiat, S., Durbano, A., Peignon, C., Mou-Tham, G., Ham, J., Antoine De Ramon, N.Y., 2020. Citizen science, a promising tool for detecting and monitoring outbreaks of the crown-of-thorns starfish Acanthaster. Sci. Rep. 10 (1), 1-10.

Dutta, P., Aoki, P.M., Kumar, N., Mainwaring, A., Myers, C., Willett, W., Woodruff, A., 2009. Common sense: participatory urban sensing using a network of handheld air quality monitors. Proceedings of the 7th ACM conference on embedded networked sensor systems, pp. 349-350.

Duyzer, J., van den Hout, D., Zandveld, P., van Ratingen, S., 2015. Representativeness of air quality monitoring networks. Atmos. Environ. 104, 88-101.

Eeftens, M., Tsai, M.Y., Ampe, C., Anwander, B., Beelen, R., Bellander, T., De Nazelle, A., 2012. Spatial variation of PM2. 5, PM10, PM2. 5 absorbance and PMcoarse concentrations between and within 20 European study areas and the relationship with $\mathrm{NO}_{2}-$ results of the ESCAPE project. Atmos. Environ. 62, 303-317.

English, P.B., et al., 2017. The Imperial County Community Air Monitoring Network: a model for community-based environmental monitoring for public health action. Environ. Health Perspect. 125, 074501.

ESCAPE (European Study of Cohorts for Air Pollution Effects). 2013. Manuals. Available: http://www.escapeproject.eu/manuals [Accessed: December 20, 2020].

Eurobarometer. (2019). Attitudes of Europeans towards Air Quality. Special Eurobarometer 497.

European Environment Agency. (2012). Urban Atlas 2012 [Dataset]. Copernicus Land Monitoring Service. https://land.copernicus.eu/local/urban-atlas [Accessed: March 29, 2021]

European Environmental Agency (2019a). Air Quality in Europe - 2019 Report. European Environment Agency: No 10/2019.

European Environment Agency (2019b). Assessing air quality through citizen science. EEA Report No 19/2019.

Fairclough, D.V., Brown, J.I., Carlish, B.J., Crisafulli, B.M., Keay, I.S., 2014. Breathing life into fisheries stock assessments with citizen science. Sci. Rep. 4, 7249.

Fritz, S., See, L., Carlson, T., Haklay, M.M., Oliver, J.L., Fraisl, D., Wehn, U., 2019. Citizen science and the United Nations sustainable development goals. Nature Sustain. 2 (10), 922-930.

Garcia-Martí, I., Zurita-Milla, R., Harms, M.G., Swart, A., 2018. Using volunteered observations to map human exposure to ticks. Sci. Rep. 8 (1), 15435

Global Burden of Disease Collaborative Network. Global Burden of Disease Study 2016 (GBD 2016) Results. Seattle, United States: Institute for Health Metrics and Evaluation (IHME), 2017.

Golumbic, Y.N., Fishbain, B., Baram-Tsabari, A., 2019. User centered design of a citizen science air-quality monitoring project. Int. J. Sci. Educ., Part B 9 (3), 195-213.

Guerrini, C.J., Majumder, M.A., Lewellyn, M.J., McGuire, A.L., 2018. Citizen science, public policy. Science 361 (6398), 134-136.

Gutiérrez-Roig, M., Sagarra, O., Oltra, A., Palmer, J.R., Bartumeus, F., Díaz-Guilera, A. Perelló, J., 2016. Active and reactive behaviour in human mobility: the influence of attraction points on pedestrians. R. Soc. Open Sci. 3 (7), 160177.

Hafkenscheid, T., Fromage-Marriette, A., Goelen, E., Hangartner, M., Pfeffer, U., Plaisance, H., Gerboles, M., 2009. Review of the application of diffusive samplers for the measurement of nitrogen dioxide in ambient air in the European Union. Institute for Environment and Sustainability. Office for Official Publications of the European Communities, Luxembourg.

Haklay, M., 2015. Citizen Science and Policy: A European Perspective. Woodrow Wilson International Center for Scholars, Washington, DC https://www.wilsoncenter.org/ sites/default/files/Citizen_Science_Policy_European_Perspective_Haklay.pdf.

Haklay, M., Eleta, I., 2019. On the front line of community-led air quality monitoring. Integrating Human Health into Urban and Transport Planning. Springer, Cham, pp. $563-580$

Haywood, B.K., Parrish, J.K., Dolliver, J., 2016. Place-based and data-rich citizen science as a precursor for conservation action. Conserv. Biol. 30 (3), 476-486.

Hecker, S., Wicke, N., Haklay, M., Bonn, A., 2019. How does policy conceptualise citizen science? A qualitative content analysis of international policy documents. Citizen Sci. Theory Pract. 4 (1)

Heigl, F., Kieslinger, B., Paul, K.T., Uhlik, J., Dörler, D., 2019. Opinion: toward an international definition of citizen science. Proc. Natl. Acad. Sci. 116 (17), 8089-8092.

Hoek, G., Beelen, R., De Hoogh, K., Vienneau, D., Gulliver, J., Fischer, P., Briggs, D., 2008. A review of land-use regression models to assess spatial variation of outdoor air pollution. Atmos. Environ. 42 (33), 7561-7578.

Hsu, Y.C., Dille, P., Cross, J., Dias, B., Sargent, R., Nourbakhsh, I., 2017. Communityempowered air quality monitoring system. Proceedings of the $2017 \mathrm{CHI}$ Conference on Human Factors in Computing Systems, pp. 1607-1619.

ICC. Buildings map for Barcelona. [Topographic map 1:5000]. Institut Cartogràfic de Catalunya (ICC). [Accessed: March 2015]. 
Idescat (2018). GRID DE POBLACIÓ PER CATALUNYA PER L'ANY 2016. [Map]. Idescat. Accessed: January 24,2018 , from https://www.idescat.cat/cataleg/?tc $=c \& i d p=172$

Idescat (2019). https://www.idescat.cat/emex/?id=080193 [Accessed: September 7, 2020].

INE (2017). Renda tributària mitjana per persona de la ciutat de Barcelona en base al projecte experimental Atles de distribució de la renda de les llars de l'Institut Nacional d'Estadística (INE). https://opendata-ajuntament.barcelona.cat/data/ca/ dataset/renda-tributaria-per-persona-atlas-distribucio/resource/d6bb4f5e-d719447d-b6e8-5e3be2f710f2 [Accessed: September 7, 2020].

InfoK. (2018, 28 February) Mesurem la qualitat de l'aire de Barcelona https://www.ccma. cat/video/embed/super3/5734607/ (Video: 1m49s) [Accessed: March 29, 2021].

Instituto Nacional de Estadística, 2011. Censos de Población y Viviendas 2011. Resultados Nacionales, por Comunidades Autónomas y Provincias.

Irwin, A., 2018. No PhDs needed: how citizen science is transforming research. Nature $562,480-482$.

Jerrett, M., Donaire-Gonzalez, D., Popoola, O., Jones, R., Cohen, R.C., Almanza, E., TrigueroMas, M., 2017. Validating novel air pollution sensors to improve exposure estimates for epidemiological analyses and citizen science. Environ. Res. 158, 286-294.

Jetz, W., McGeoch, M.A., Guralnick, R., Ferrier, S., Beck, J., Costello, M.J., Meyer, C., 2019. Essential biodiversity variables for mapping and monitoring species populations. Nat. Ecol. Evol. 3 (4), 539-551.

Johnson, M., Isakov, V., Touma, J.S., Mukerjee, S., Özkaynak, H., 2010. Evaluation of landuse regression models used to predict air quality concentrations in an urban area. Atmos. Environ. 44, 3660e3668.

Johnson, M.F., Hannah, C., Acton, L., Popovici, R., Karanth, K.K., Weinthal, E., 2014. Network environmentalism: citizen scientists as agents for environmental advocacy. Glob. Environ. Chang. 29, 235-245.

Johnson, B.J., Brosch, D., Christiansen, A., Wells, E., Wells, M., Bhandoola, A.F., Fonseca, D.M., 2018. Neighbors help neighbors control urban mosquitoes. Sci. Rep. 8 (1), 15797.

Jones, M.L., Spiers, H., 2018. The crowd storms the ivory tower. Nat. Methods 15 (8), 579.

Jordan, R.C., Sorensen, A.E., Biehler, D., Wilson, S., LaDeau, S., 2019. Citizen science and civic ecology: merging paths to stewardship. J. Environ. Stud. Sci. 9 (1), 133-143.

Kallimanis, A.S., Panitsa, M., Dimopoulos, P., 2017. Quality of non-expert citizen science data collected for habitat type conservation status assessment in Natura 2000 protected areas. Sci. Rep. 7 (1), 8873.

Khreis, H., et al., 2017. Exposure to traffic-related air pollution and risk of development of childhood asthma: a systematic review and meta-analysis. Environ. Int. 100, 1-31.

Kloetzer, L., Jennett, C., Francis, L., Haklay, M., 2017. Community engagement around poor air quality in London: citizen inquiry in a citizen science "mapping for change" project. Citizen Inquiry. Routledge, pp. 42-62.

Koepnick, B., Flatten, J., Husain, T., Ford, A., Silva, D.A., Bick, M.J., Estep, R.D., 2019. De novo protein design by citizen scientists. Nature 570 (7761), 390-394.

Kosmala, M., Wiggins, A., Swanson, A., Simmons, B., 2016. Assessing data quality in citizen science. Front. Ecol. Environ. 14 (10), 551-560.

Kuklinska, K., Wolska, L., Namiesnik, J., 2015. Air quality policy in the US and the EU-a review. Atmos. Pollut. Res. 6 (1), 129-137.

Kullenberg, C., 2015. Citizen science as resistance: crossing the boundary between reference and representation. J. Resist. Stud. 1 (1), 50-76.

Kumar, P., Morawska, L., Martani, C., Biskos, G., Neophytou, M., Di Sabatino, S., Britter, R., 2015. The rise of low-cost sensing for managing air pollution in cities. Environ. Int. 75, 199-205.

Landrigan, P.J., Fuller, R., Acosta, N.J., Adeyi, O., Arnold, R., Baldé, A.B., Chiles, T., 2018. The lancet commission on pollution and health. Lancet 391 (10119), 462-512.

Languille, B., Gros, V., Bonnaire, N., Pommier, C., Honoré, C., Debert, C., Zeitouni, K., 2020. A methodology for the characterization of portable sensors for air quality measure with the goal of deployment in citizen science. Sci. Total Environ. 708, 134698.

LAQMTG16, 2018. Local Air Quality Management Technical Guidance (TG16). Department for Environment, Food and Rural Affairs, London, United Kingdom.

Lin, C., Feng, X., Heal, M.R., 2016. Temporal persistence of intra-urban spatial contrasts in ambient $\mathrm{NO}_{2}, \mathrm{O} 3$ and $\mathrm{Ox}$ in Edinburgh, UK. Atmos. Pollut. Res. 7 (4), 734-741.

Longo, A., Zappatore, M., Bochicchio, M.A., 2020. Apollon: Towards a Citizen Science Methodology for Urban Environmental Monitoring. Future Generation Computer Systems.

Lukyanenko, R., Wiggins, A., Rosser, H.K., 2019. Citizen Science: An Information Quality Research Frontier. Information Systems Frontiers, pp. 1-23.

MacDonald, E.A., Donovan, E., Nishimura, Y., Case, N.A., Gillies, D.M., Gallardo-Lacourt, B., ... Heavner, M., 2018. New science in plain sight: citizen scientists lead to the discovery of optical structure in the upper atmosphere. Sci. Adv 4 (3), eaaq0030.

Mahajan, S., Kumar, P., Pinto, J.A., Riccetti, A., Schaaf, K., Camprodon, G., Forino, G., 2020. A citizen science approach for enhancing public understanding of air pollution. Sustain. Cities Soc. 52, 101800.

Mehr, S.A., Singh, M., Knox, D., Ketter, D.M., Pickens-Jones, D., Atwood, S., Howard, R.M., 2019. Universality and diversity in human song. Science 366 (6468).

Mijling, B., Jiang, Q., De Jonge, D., Bocconi, S., 2018. Field calibration of electrochemical NO 2 sensors in a citizen science context. Atmos. Meas. Tech. 11 (3), 1297-1312.

Miller, E.T., Leighton, G.M., Freeman, B.G., Lees, A.C., Ligon, R.A., 2019. Ecological and geographical overlap drive plumage evolution and mimicry in woodpeckers. Nat. Commun. 10 (1), 1602.

Mineco 2020. https://www.miteco.gob.es/es/calidad-y-evaluacion-ambiental/temas/ atmosfera-y-calidad-del-aire/cleanairschools-girona-2019_tcm30-509918.pdf [Accessed: July 29, 2020].

Nieuwenhuijsen, M.J., 2016. Urban and transport planning, environmental exposures and health-new concepts, methods and tools to improve health in cities. Environ. Health 15 (1), S38.
Padró Barcelona (2018). Ajuntament de Barcelona. Departament d'Estadística i Difusió de Dades. Lectura del Padró Municipal d'Habitants a 1 gener 2018. https://www.bcn.cat/ estadistica/catala/dades/tpob/pad/padro/a2018/llocna/llocna11.htm [Accessed: September 7, 2020].

Palmer, J.R., Oltra, A., Collantes, F., Delgado, J.A., Lucientes, J., Delacour, S., Bartumeus, F., 2017. Citizen science provides a reliable and scalable tool to track disease-carrying mosquitoes. Nat. Commun. 8 (1), 916

Palmes, E.D., Gunnison, A.F., DiMattio, J., Tomczyk, C., 1976. Personal sampler for nitrogen dioxide. Am. Ind. Hyg. Assoc. J. 37 (10), 570-577.

Parrish, J.K., Jones, T., Burgess, H.K., He, Y., Fortson, L., Cavalier, D., 2019. Hoping for optimality or designing for inclusion: persistence, learning, and the social network of citizen science. Proc. Natl. Acad. Sci. 116 (6), 1894-1901.

Perelló, J., Murray-Rust, D., Nowak, A., Bishop, S.R., 2012. Linking science and arts: intimate science, shared spaces and living experiments. Eur. Phys. J. Spec. Top. 214 (1), 597-634.

Perelló, J., Ferran-Ferrer, N., Ferré, S., Pou, T., Bonhoure, I., 2017. High Motivation and Relevant Scientific Competencies through the Introduction of Citizen Science at Secondary Schools. In: Herodotou, C., Sharples, M., Scanlon, E. (Eds.), Citizen inquiry: synthesising science and inquiry learning. 2017. Routledge, London, pp. 150-175.

Perelló, J., Targa, J., Daher, C., Alonso, M., and Masha-Caminals, A. (2018, February 11). X Aire. Guia d'ús per a centres educatius. Zenodo. https://doi.org/10.5281/ zenodo.3718949 [Accessed: March 29, 2021].

Pierangeli, I., Nieuwenhuijsen, M.J., Cirach, M., Rojas-Rueda, D., 2020. Health equity and burden of childhood asthma-related to air pollution in Barcelona. Environ. Res. 186, 1090677 pp..

Piersanti, A., Vitali, L., Righini, G., Cremona, G., Ciancarella, L., 2015. Spatial representativeness of air quality monitoring stations: a grid model based approach. Atmos. Pollut. Res. 6 (6), 953-960.

PostGIS (PostGIS Project Steering Committee, 2017) (version 2.4) [Accessed: March 29, 2021]

PostgreSQL (The PostgreSQL Global Development Group, 2017) (version 9.6.12) [Accessed: March 29, 2021]

Python Software Foundation. Python Language Reference, version 3.7. Available at http:// www.python.org. [Accessed: March 29, 2021]

QGIS Development Team, 2009. QGIS geographic information system. Version 3.12. Open Source Geospatial Foundation. URL http://qgis.org [Accessed: March 29, 2021].

R Core Team. R: A language and environment for statistical computing. Vienna, Austria, 2019 https://www.R-project.org/. [Accessed: March 29, 2021].

Ripoll, A., Viana, M., Padrosa, M., Querol, X., Minutolo, A., Hou, K.M., García-Vidal, J., 2019. Testing the performance of sensors for ozone pollution monitoring in a citizen science approach. Sci. Total Environ. 651, 1166-1179.

Rojas-Rueda, D., de Nazelle, A., Teixidó, O., Nieuwenhuijsen, M.J., 2012. Replacing car trips by increasing bike and public transport in the greater Barcelona metropolitan area: a health impact assessment study. Environ. Int. 49, 100-109.

Ryan, P.H., LeMasters, G.K., 2007. A review of land-use regression models for characterizing intraurban air pollution exposure. Inhal. Toxicol. 19 (Suppl. 1), 127e133.

Sagarra, O., Gutiérrez-Roig, M., Bonhoure, I., Perelló, J., 2016. Citizen science practices for computational social science research: the conceptualization of pop-up experiments. Front. Phys. 3, 93.

Santiago, J.L., Martín, F., Martilli, A., 2013. A computational fluid dynamic modelling approach to assess the representativeness of urban monitoring stations. Sci. Total Environ. $454,61-72$.

Sauermann, H., Vohland, K., Antoniou, V., Balázs, B., Göbel, C., Karatzas, K., Winter, S., 2020. Citizen science and sustainability transitions. Res. Policy 49 (5), 103978.

Schaefer, T., Kieslinger, B., Fabian, C.M., 2020. Citizen-based air quality monitoring: the impact on individual citizen scientists and how to leverage the benefits to affect whole regions. Citizen Sci. Theory Pract. 5 (1).

Schuster, R., Wilson, S., Rodewald, A.D., Arcese, P., Fink, D., Auer, T., Bennett, J.R., 2019. Optimizing the conservation of migratory species over their full annual cycle. Nat. Commun. 10 (1), 1754

Senabre, E., Ferran-Ferrer, N., Perelló, J., 2018. Participatory design of citizen science experiments. Comunicar. Media Educ. Res. J. 26 (1).

Shanley, L.A., Parker, A., Schade, S., Bonn, A., 2019. Policy perspectives on citizen science and crowdsourcing. Citizen Sci. Theory Pract. 4 (1).

Síndic de Greuges de Catalunya. La qualitat de l'aire a Catalunya: dèficits i recomanacions. Juny 2019. http://www.sindic.cat/site/unitFiles/6328/Informe|\%20qualitat|\%20aire_ cat_ok.pdf [Accessed: August 31, 2021].

Steed, R.J., Fuenzalida, A., Bossu, R., Bondár, I., Heinloo, A., Dupont, A., ... Strollo, A., 2019. Crowdsourcing triggers rapid, reliable earthquake locations. Sci. Adv 5 (4), eaau9824.

Steiner, S.M., 2020. Popular epidemiology and community-based citizen science: using a bio-indicator for toxic air pollution. SAGE Research Methods Cases https://doi.org/ $10.4135 / 9781529710748$

Stern, P.C., 2000. New environmental theories: toward a coherent theory of environmentally significant behavior. J. Soc. Issues 56 (3), 407-424.

Sunyer, J., Esnaola, M., Alvarez-Pedrerol, M., Forns, J., Rivas, I., López-Vicente, M., Viana, M. 2015. Association between traffic-related air pollution in schools and cognitive development in primary school children: a prospective cohort study. PLoS Med. 12 (3), e1001792.

Targa, J., Loader, A., 2008. Diffusion tubes for ambient $\mathrm{NO}_{2}$ monitoring: practical guidance for laboratories and users. Report to Defra and the Devolved Administrations. AEA Energy and Environment, Harwell.

Tiago, P., Ceia-Hasse, A., Marques, T.A., Capinha, C., Pereira, H.M., 2017. Spatial distribution of citizen science casuistic observations for different taxonomic groups. Sci. Rep. 7 (1), 12832 . 
USEPA. (2016). Environmental Protection Belongs to the Public: A Vision for Citizen Science at EPA. https://www.epa.gov/sites/production/files/2016-12/documents/ nacept_cs_report_final_508_0.pdf [Retrieved 9th of March 2020]

Van Brussel, S., Huyse, H., 2019. Citizen science on speed? Realising the triple objective of scientific rigour, policy influence and deep citizen engagement in a large-scale citizen science project on ambient air quality in Antwerp. J. Environ. Plan. Manag. 62 (3), 534-551.

Van den Bossche, J., Theunis, J., Elen, B., Peters, J., Botteldooren, D., De Baets, B., 2016. Opportunistic mobile air pollution monitoring: a case study with city wardens in Antwerp. Atmos. Environ. 141, 408-421.

Vardoulakis, S., Fisher, B.E., Pericleous, K., Gonzalez-Flesca, N., 2003. Modelling air quality in street canyons: a review. Atmos. Environ. 37 (2), 155-182.

Vardoulakis, S., Gonzalez-Flesca, N., Fisher, B.E., Pericleous, K., 2005. Spatial variability of air pollution in the vicinity of a permanent monitoring station in central Paris. Atmos. Environ. 39 (15), 2725-2736.

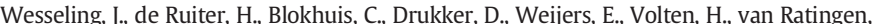
S., 2019. Development and implementation of a platform for public information on air quality, sensor measurements, and citizen science. Atmosphere 10 (8), 445.

West, S.E., Büker, P., Ashmore, M., Njoroge, G., Welden, N., Muhoza, C., Apondo, W., 2020. Particulate matter pollution in an informal settlement in Nairobi: using citizen science to make the invisible visible. Appl. Geogr. 114, 102133.

Wong, M., Bejarano, E., Carvlin, G., Fellows, K., King, G., Lugo, H., Jerrett, M., Meltzer, D., Northcross, A., Olmedo, L., Seto, E., Wilkie, A., English, P., 2018 Mar 15. Combining community engagement and scientific approaches in next-generation monitor siting: the case of the Imperial County Community Air Network. Int. J. Environ. Res. Public Health 15 (3), 523.

World Health Organization, 2006. WHO Air Quality Guidelines for Particulate Matter, Ozone, Nitrogen Dioxide and Sulfur Dioxide-Global Update 2005-Summary of Risk Assessment. WHO, Geneva.

World Health Organization. (2018). WHO global ambient air quality database (update 2018). World Health Organization: Geneva, Switzerland.

Wu, H., Reis, S., Lin, C., Beverland, I.J., Heal, M.R., 2015. Identifying drivers for the intraurban spatial variability of airborne particulate matter components and their interrelationships. Atmos. Environ. 112, 306-316.

xAire (2018). Visit the website: http://xaire.communitymaps.org.uk [Accessed: March 9 2021]

xAire (2020, March 6). Monitoratge de la qualitat de l'aire a Barcelona - Presentació resultats de les escoles participants. Zenodo. https://doi.org/10.5281/ zenodo.3699613 [Accessed: March 9, 2021].

Yang, L., Li, W., Ghandehari, M., Fortino, G., 2017. People-centric cognitive internet of things for the quantitative analysis of environmental exposure. IEEE Internet Things J. 5 (4), 2353-2366.

Zhang, X., Chen, X., Zhang, X., 2018. The impact of exposure to air pollution on cognitive performance. Proc. Natl. Acad. Sci. 115 (37), 9193-9197. 